$$
\begin{aligned}
& \text { قياس خطوط الفقر ومؤشراتها في مجمعي }
\end{aligned}
$$

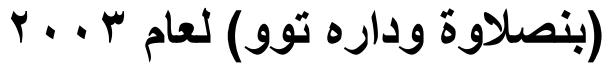

$$
\begin{aligned}
& \text { كيزخان يوسف عزيز } \\
& \text { مدرسة مساعدة ـ قسم الاقتصاد } \\
& \text { كلية الإدارة و الاقتصاد- جامعة صلاح الدين } \\
& \text { مدرس ـ قسم الاقتصاد } \\
& \text { كلية الإدارة والاقتصاد- جامعة صلاح الدين }
\end{aligned}
$$

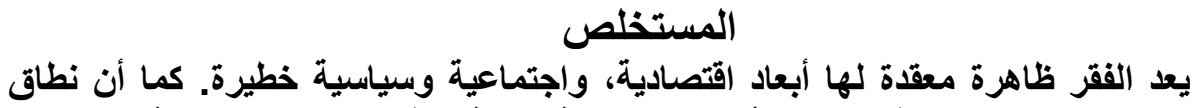

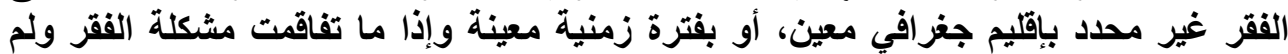

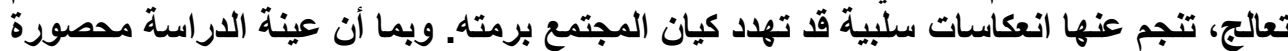

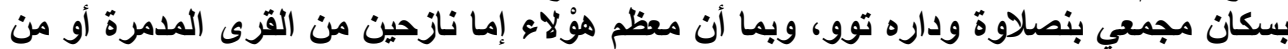

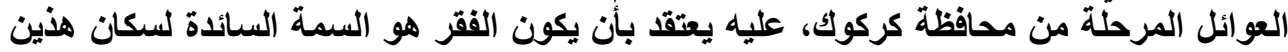

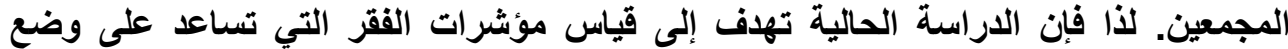

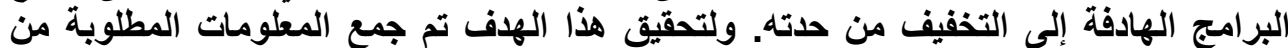

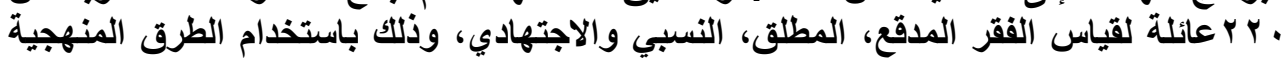

$$
\text { المعروفة. }
$$

لقد توصلت الاراسة إلى نتيجة وهي، أن الفقر ليست مشكلة حادة نسبياً في العينة

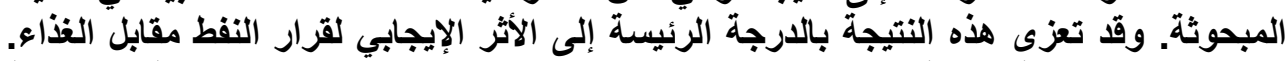

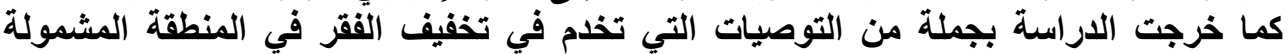
بالدراسة.

\title{
Measuring Poverty Lines and Their Indicators in Two Residential Collectives (Binasloua and Daratoo) in The Year 2003
}

Sabir P. D. Othman (PhD) Lecturer

Department of Economic University of Salah Al - Din
Khithkhan Y. Aziz

Assistant Lecturer

Department of Economic

University of Salah Al - Din

\begin{abstract}
Poverty is considered as a complex phenomenon that has economic, social and political serious dimensions. Further, poverty is not restricted to special geographical area or periods. Therefore, if the problem of poverty aggravates and is not tackled properly, it will lead to negative repercussions that might threat the society as a whole.
\end{abstract}

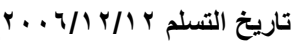


The sample of the study restricted to two residential collectives; considers that the majority of those people are emigrants from their destroyed villages or they are forcibly expelled from Kirkuk Governorate. For these reasons, poverty is expected to be a dominant characteristic in the area under consideration. So, the current study aims at measuring poverty indices which might help programs that are designed to reduce the poverty severity. Hence, the study employed objective methods to measure extreme, absolute, relative and subjective poverty.

Generally speaking, the results show that the degree of poverty is not relatively severe as one might think in the area under consideration. The result suggests that the United Nations' resolution 986 (oil for food) positively affected in the reduction of poverty. Finally, the research recommends useful suggestions that might serve to better overcome poverty in the area considered.

المقدمة

يعد الفقر ظاهرة اقتصادية، واجتماعية وسياسية، متعددة الجوانب، عميقة

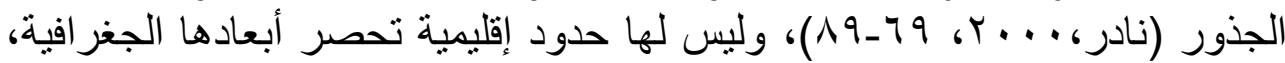

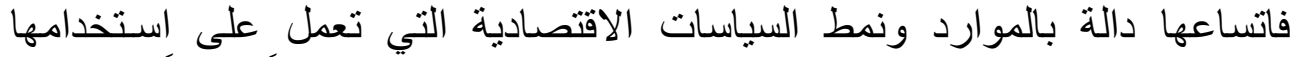

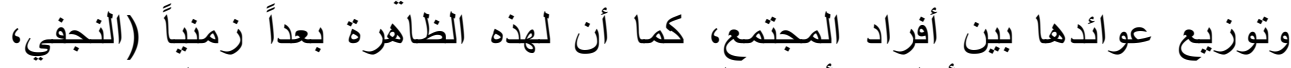

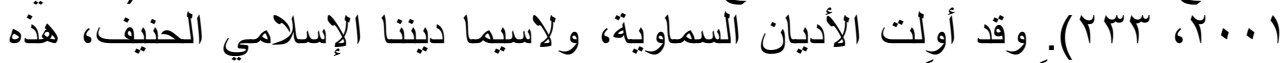

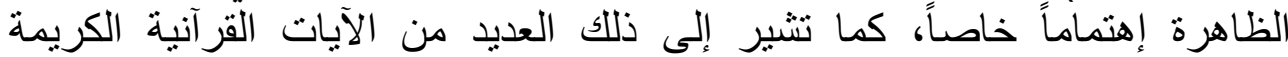

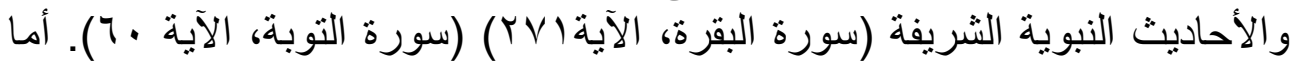

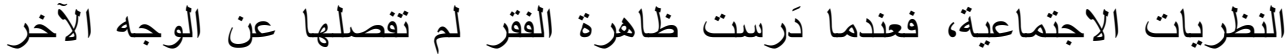

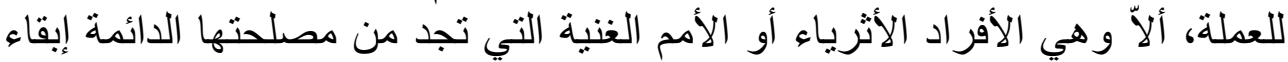

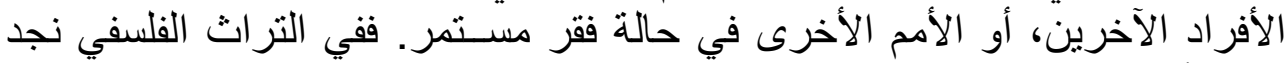

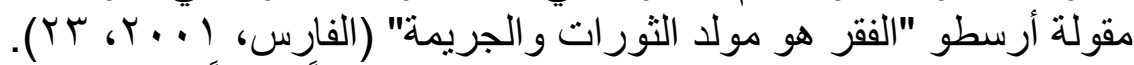

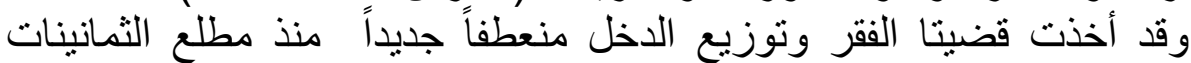

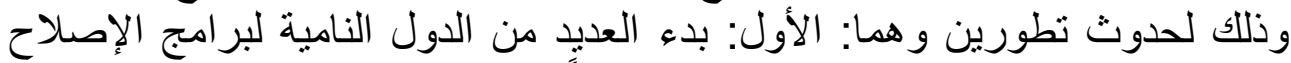

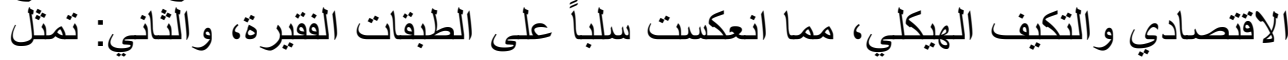

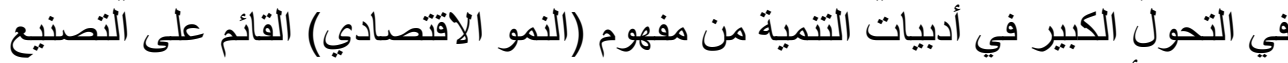

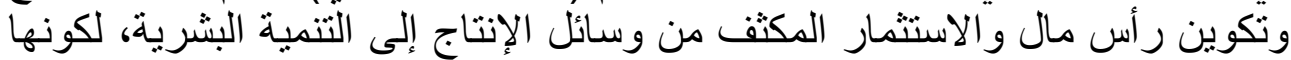

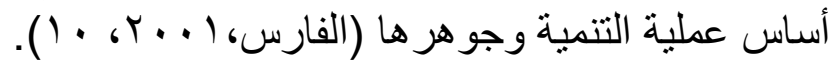

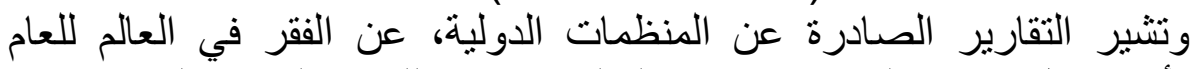

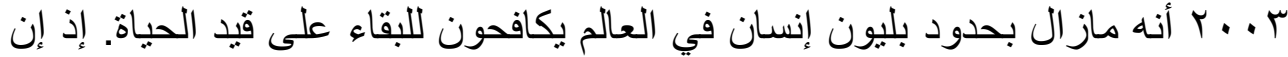

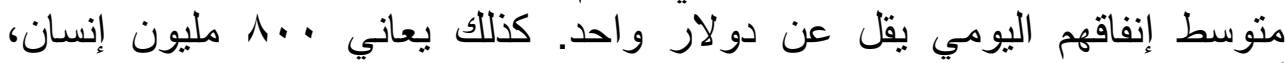

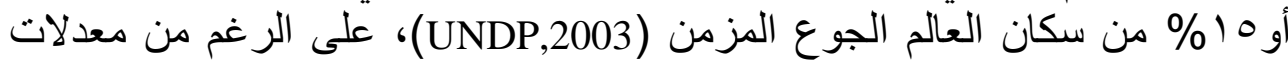

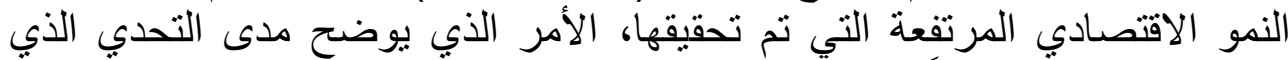

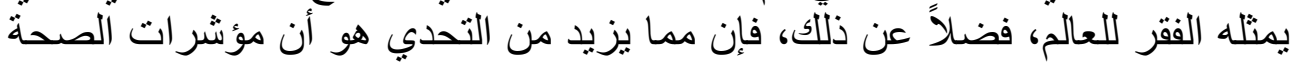

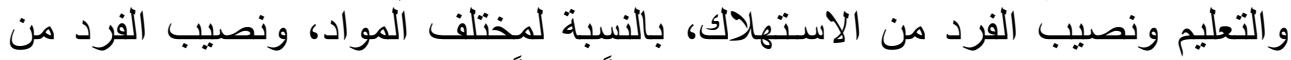

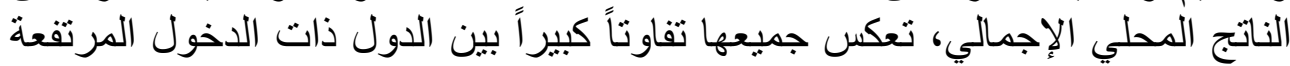
والمنخفضة (OPIC,2001,5). 
إن مؤشرات الفقر تساعد في تنخيص ظاهرة الفقر بدقة، كما أنها تساعد في كاطي

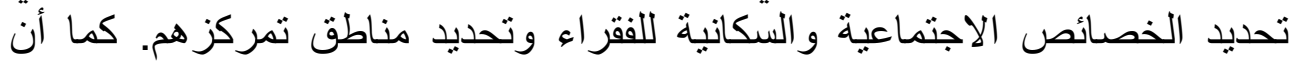

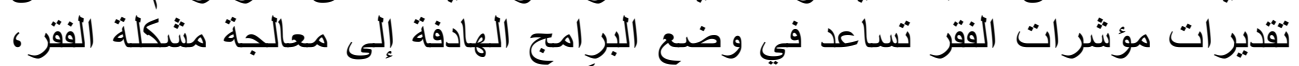

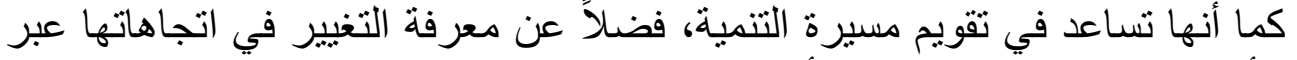

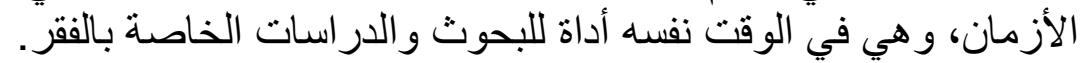

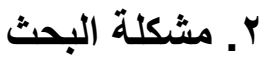

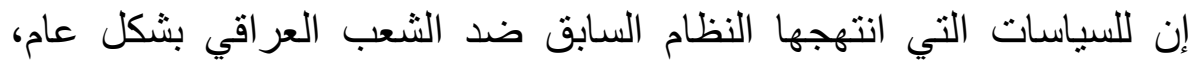

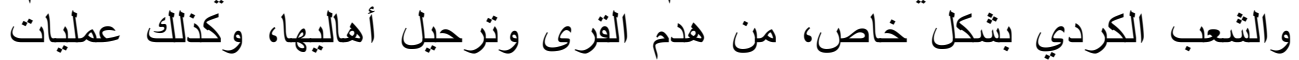

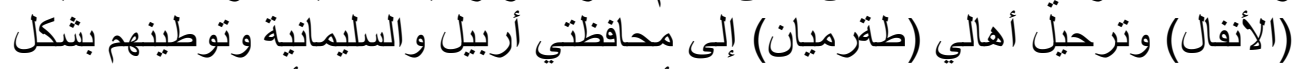

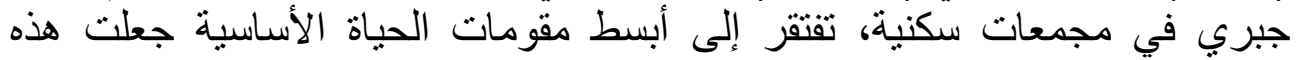

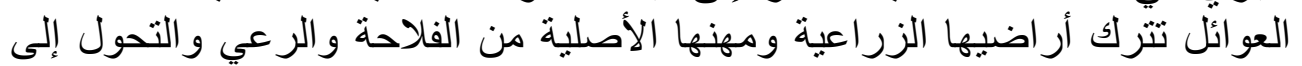

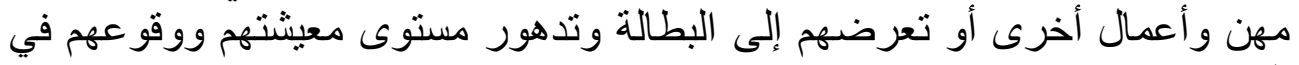
الفقر.

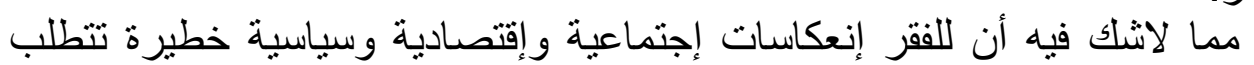
المعالجة، فضلاً عن كونه مسألة أخلاقية وإنسانية، تنتلب العمل على العلى الحد من حدته.

$$
\text { r. أهداف البحث الدراسة إلى: }
$$

أ. احتساب خطوط الفقر ومؤشراته بصيغ مختلفة بالاستناد إلى الطرق المنهجية

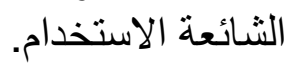
ب. تحليل مؤشرات الفقر للتوصل إلى استنتاجات معينة خاصة بظاهرة الفقر في

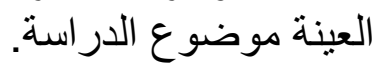
ج. التوصل إلى بعض المقلة لعترحات التي نجدها مناسبة لمعالجة هذه الظاهرة، أو قد

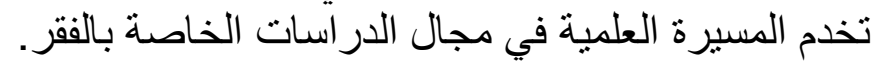

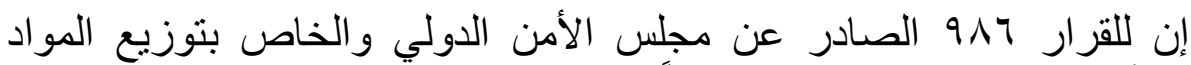

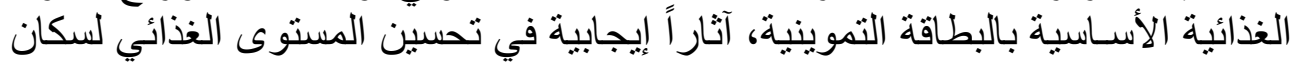

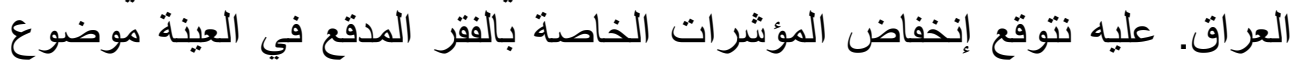

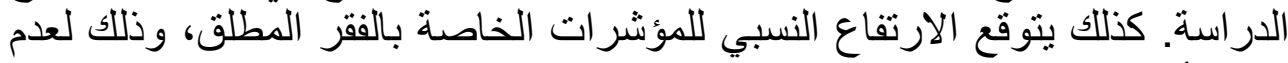

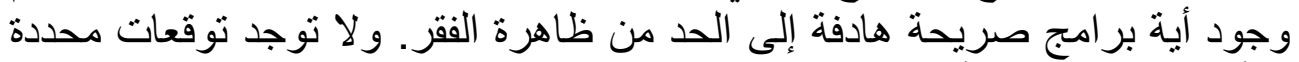

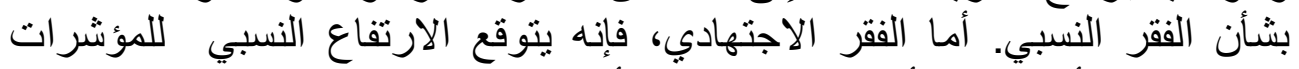

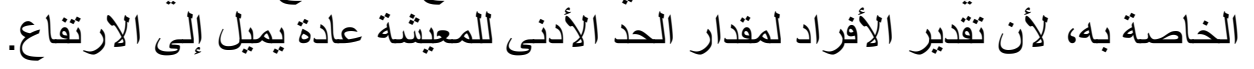


يتم استخدام الصيخ القياسية المألوفة لاحتساب خطوط الفقر، ومن ثم احتساب مؤشرات الفقر المناظرة لكل خط من خطوط الفقر المقدرة على وفق مفاهيم الفقر

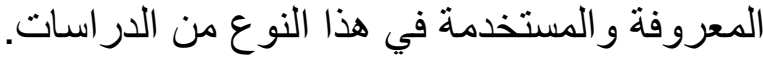

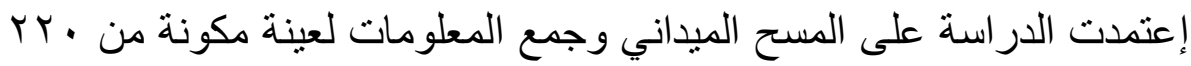

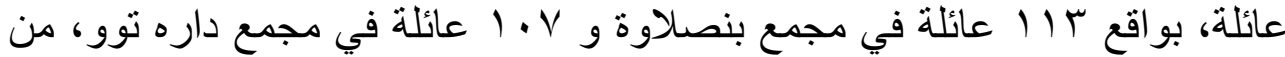

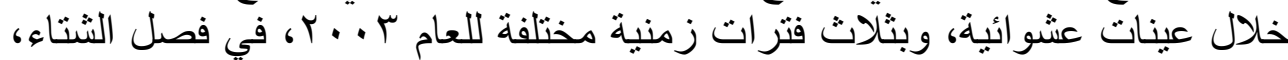

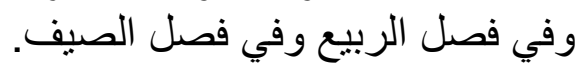
تم اختيار قضاء (ده شتي هله ولتيرَ) وتحديداً مجمعي (بنصلاوة وداره تورو) بسبب كون الفقر السمة الظاهرة لسكان هذين المجمعين. ونم استخدام متوسط الإنفاق

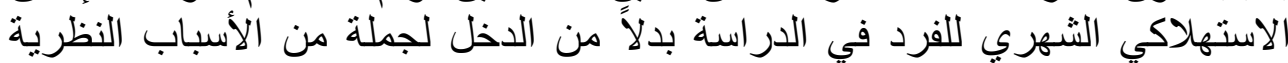

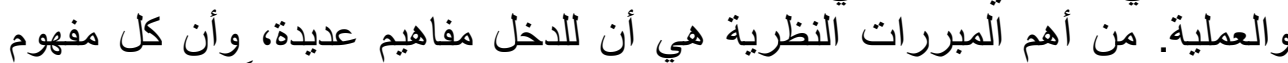

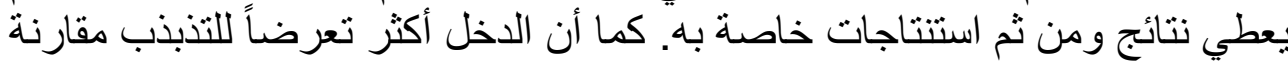

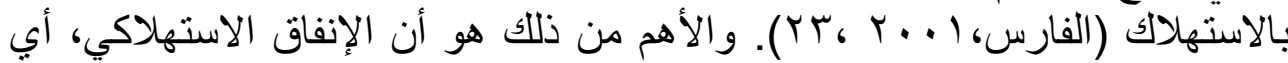

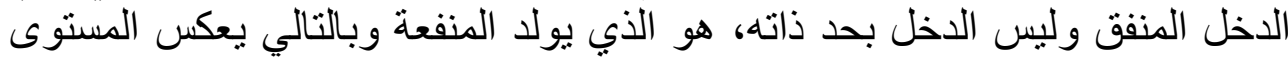
الحقيقي للمعيشة ( Atkinson,1975,39).

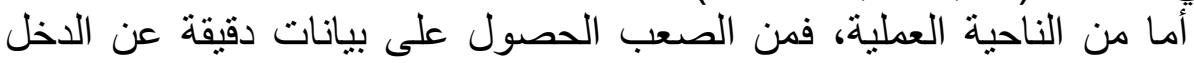

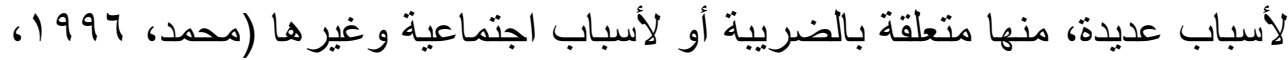

إن مبرر استخدام الفرد وحدة للتحليل بدلاً من الأسرة هو أن أفراد الأسرة

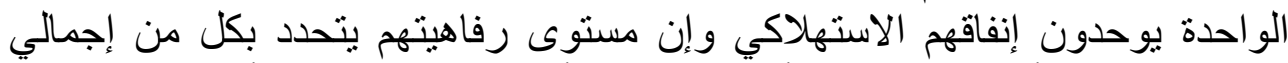

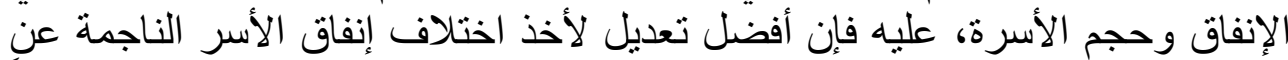

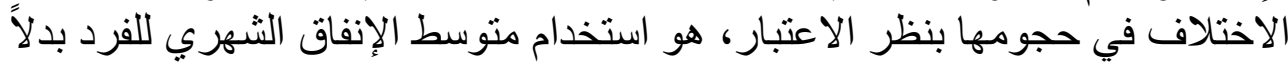
من الأسرة (محمد، 1997 (، بون).

\section{توصيف وصياغة إنموذج التحليل}

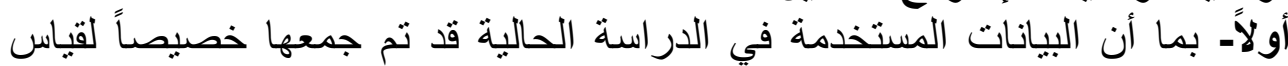

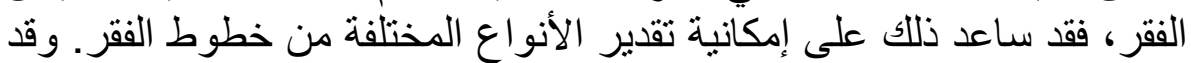

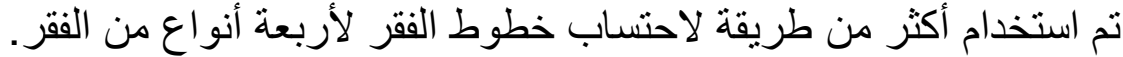

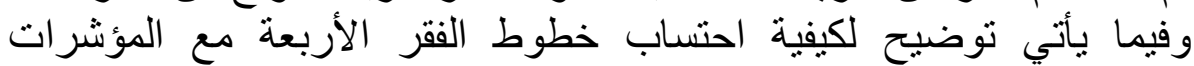

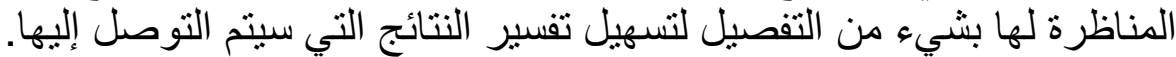

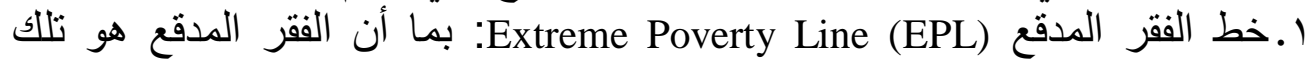

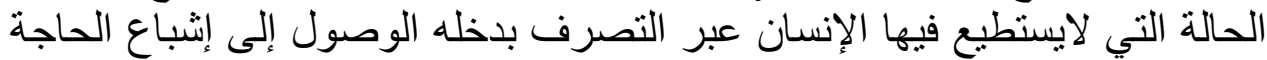

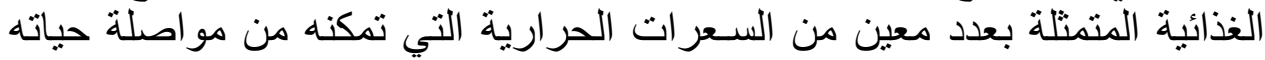
عند حدود معينة، عليه فإن خط الفقر المدقع يمثل كلفة تغطية تلك الكين الحاجات، الغذائية 


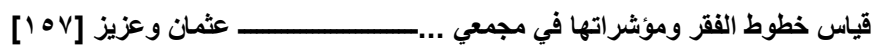

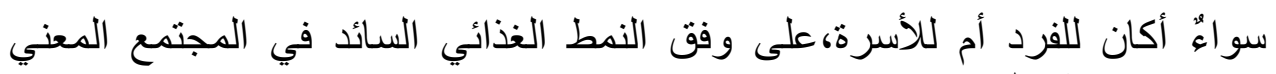

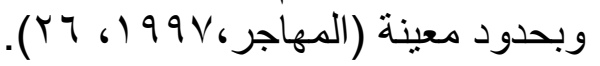

لقد اعتمدت الدراسة الحالية ثلاثة أساليب مختلفة لتحديد خط الفقر المدقع. كما

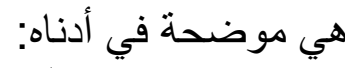

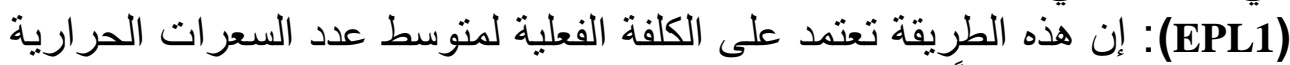

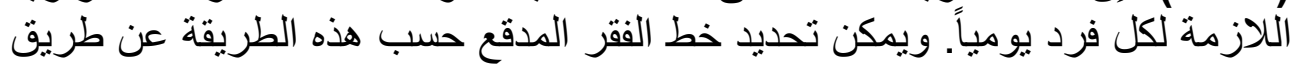
احتساب تكلفة السعرة الحرارية الواحدة على بلى وفق نمط الحياة السائدة في عينة متوسط الإنفاق الفردي الثهري على المواد الغذائية

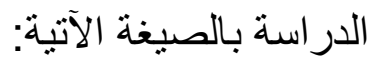
تكلفة السعرة الحرارية الواحدة = متوسط عدد السعرات الحرارية الثهرية المكتسبة الإنقلى الفردي الثهري على الثذانة

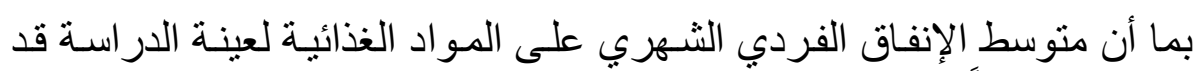

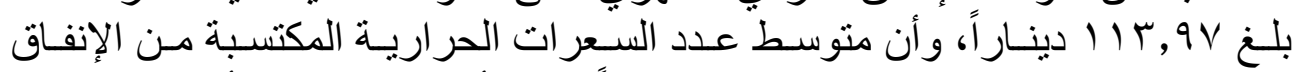

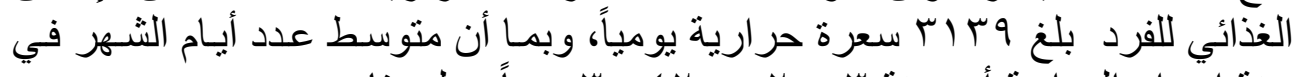

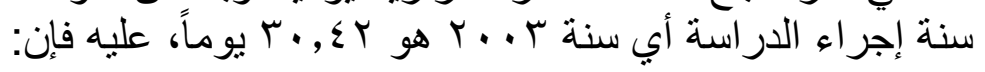

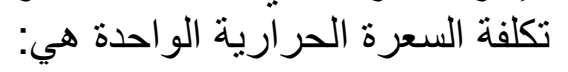

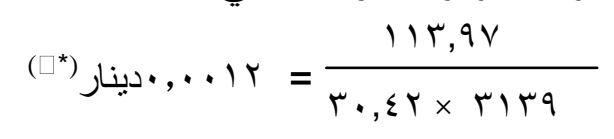

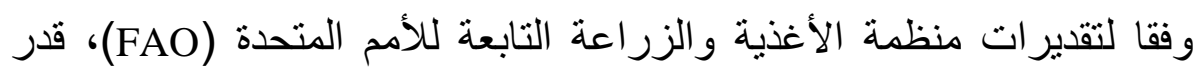

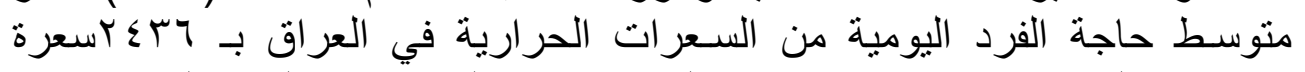

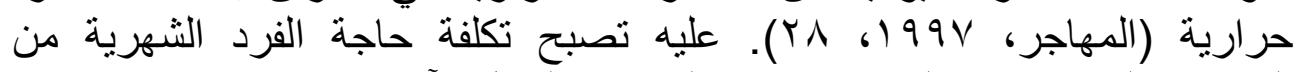

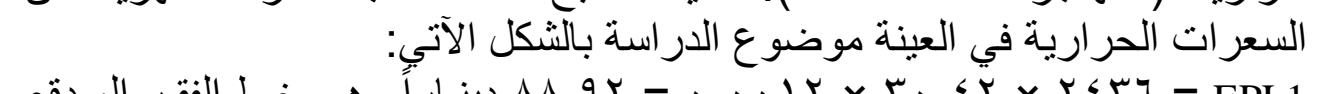
الاول = EPL1

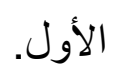

و هذا يعني أنه إذا كان متوسط الإنفاق الفردي الثهري على الغذاء لأية أسرة

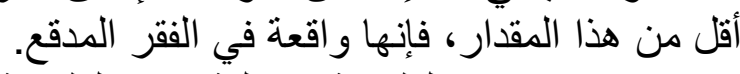

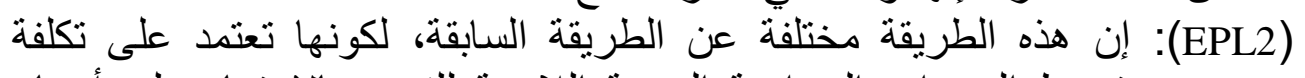

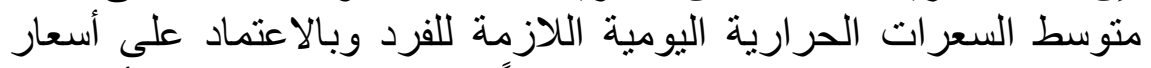

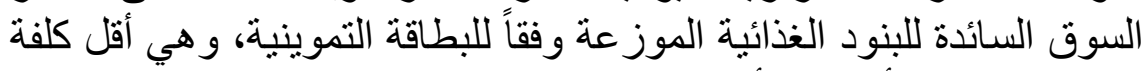

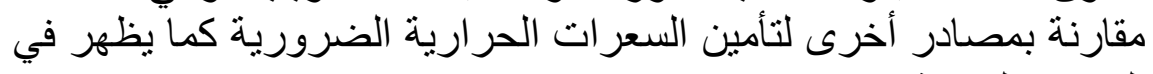
الفقر ات اللاحقة.

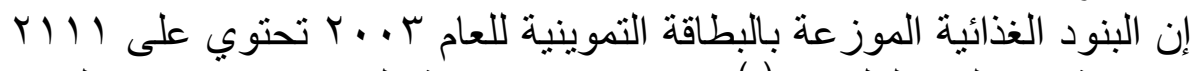

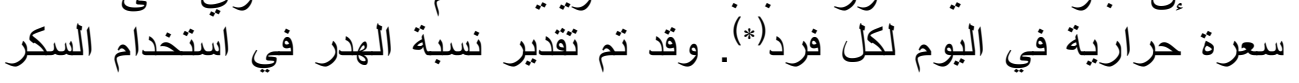

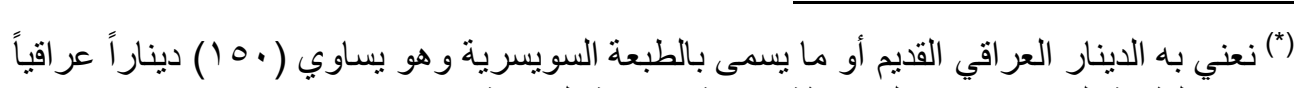
من الطبعة الجيدة، وهذه الملاحظة سارية في بقية الدراسة. 


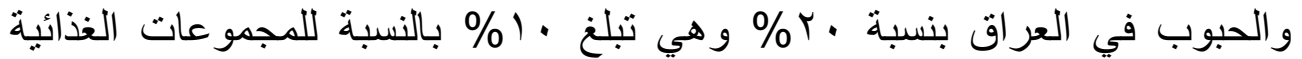

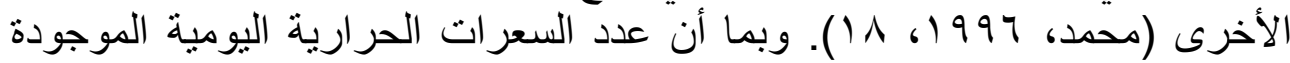

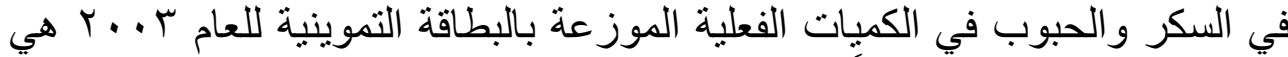

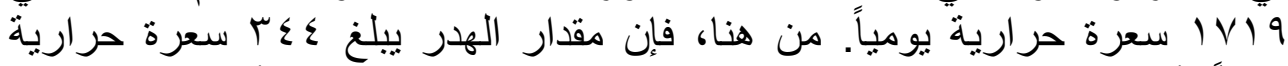

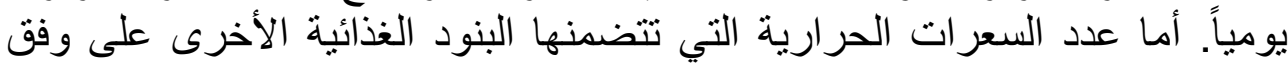

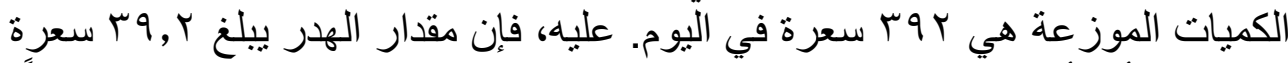

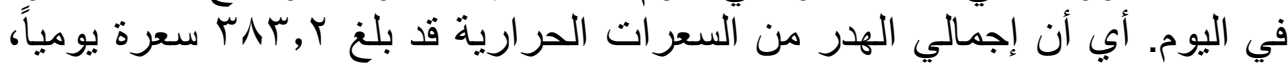

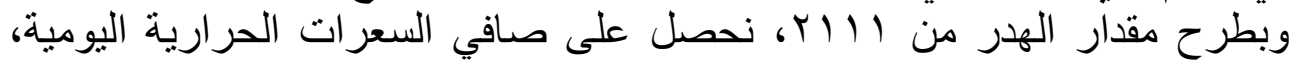

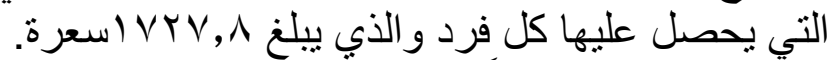

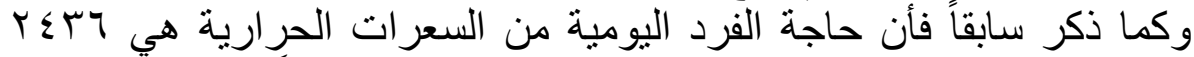

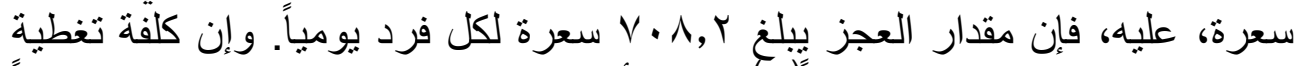

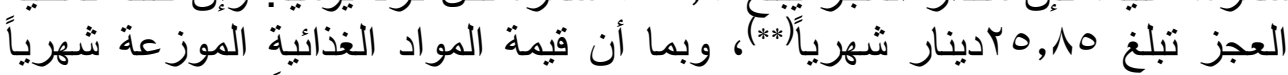

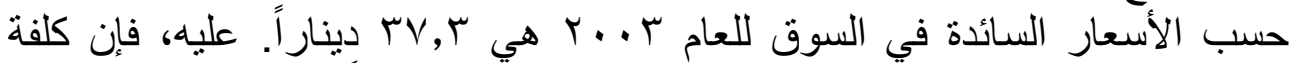
تغطية كامل احتباجات الفرد من السعرات الحرارية شهرياً التي تمثل خط التهان الفقر

$$
\text { . }
$$$$
\text { المدقع الثاني هي: - إني }
$$

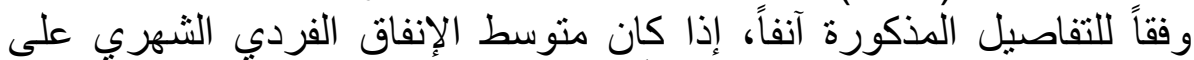

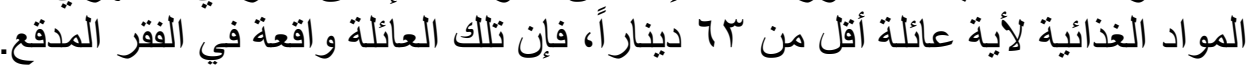
(EPL3)

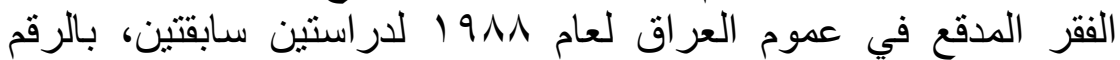

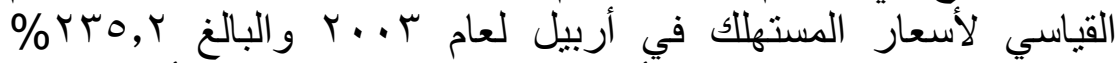

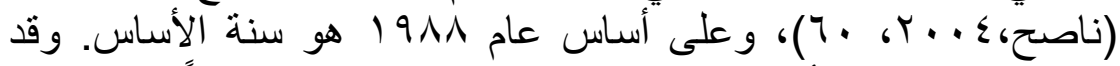

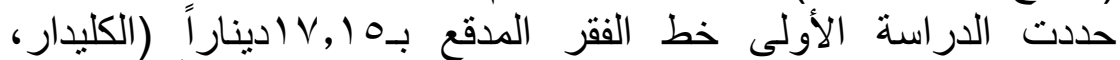

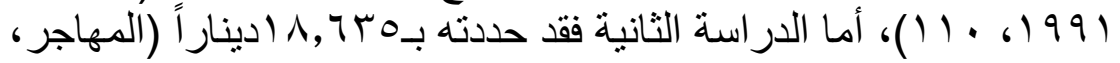

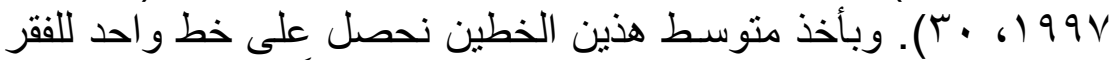

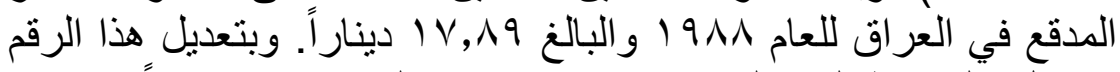

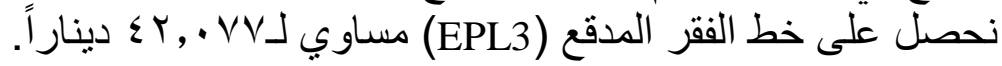

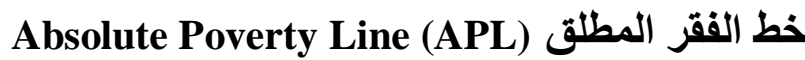

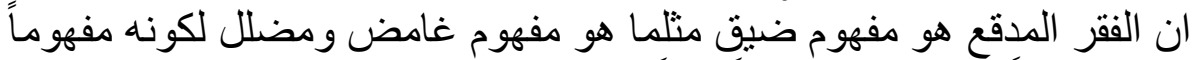

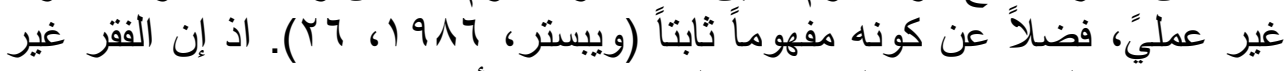

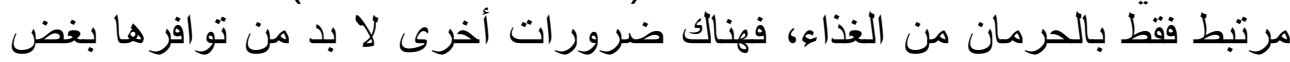

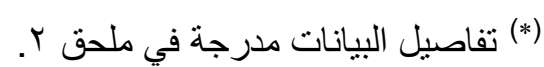

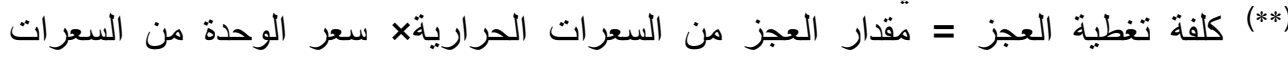

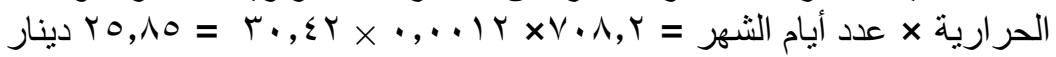


قياس خطوط الفقر ومؤشر اتها في مجمعي .... _.

النظر عن الزمان و المكان، فضلاً عن ذللك، فإن تلك الضرورات تتغير عبر الزمن وباختلاف المجتمعات.

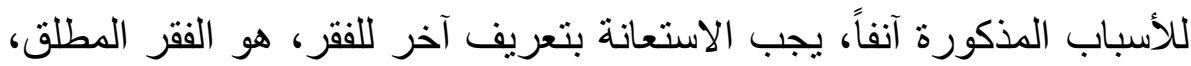

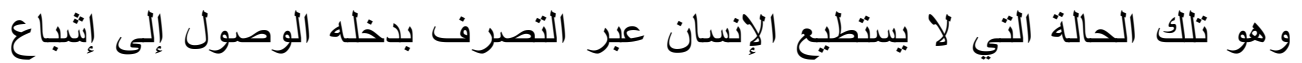

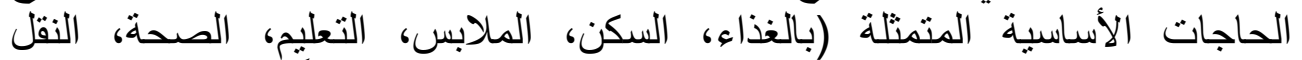

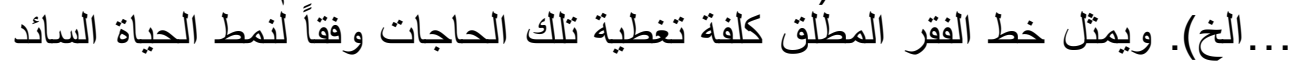

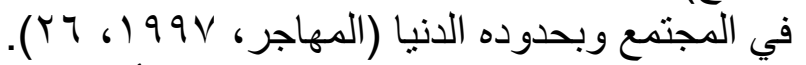

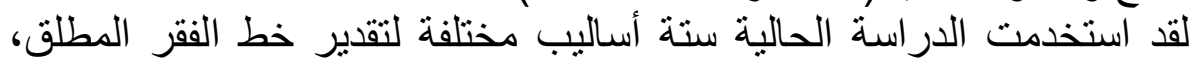

وهي موضحة أدناه: - (APL1)

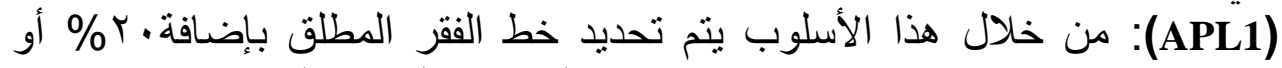

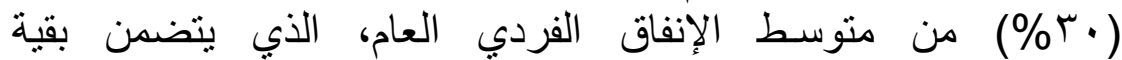

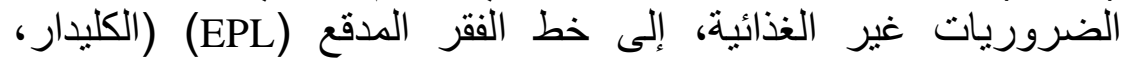

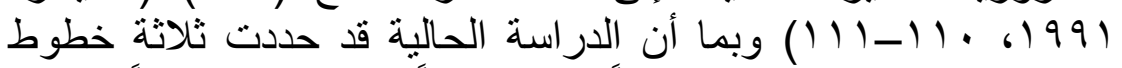

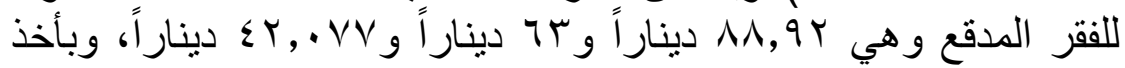

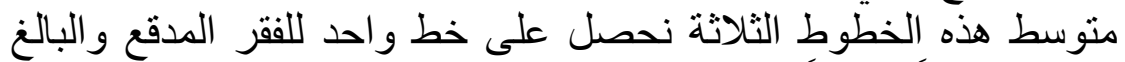

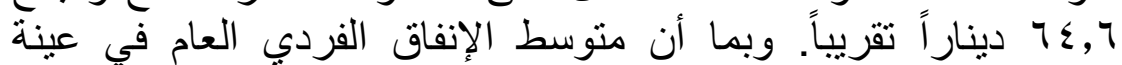

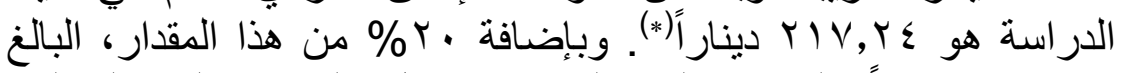

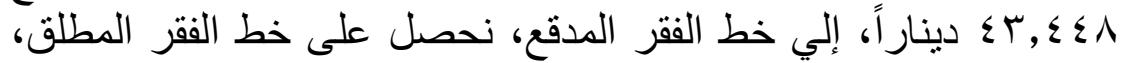

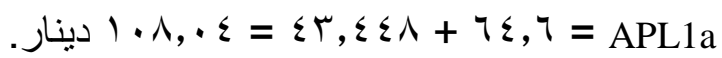

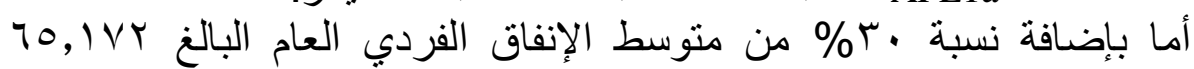

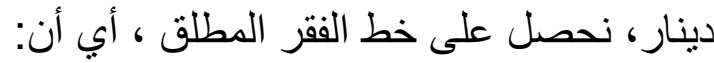

. 1 ا دينار

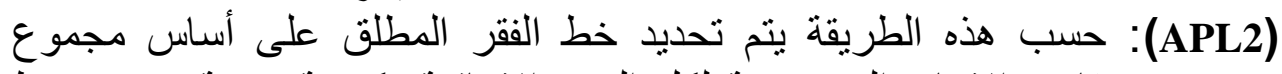

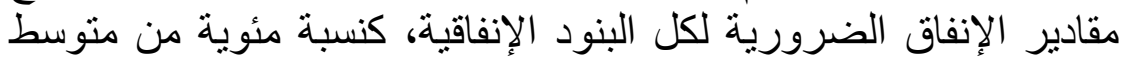

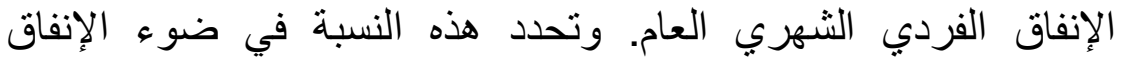

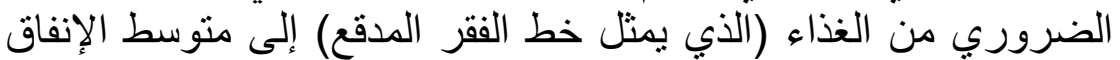

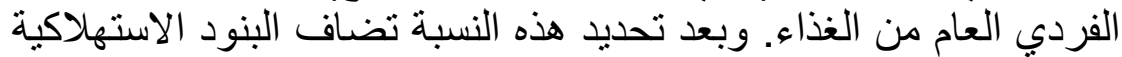

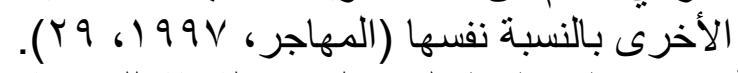

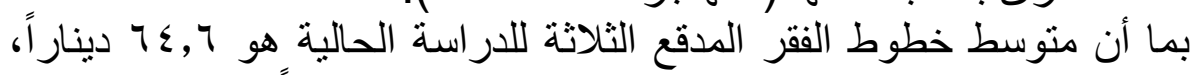

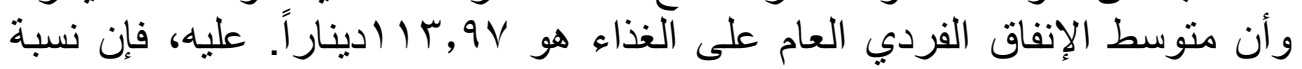

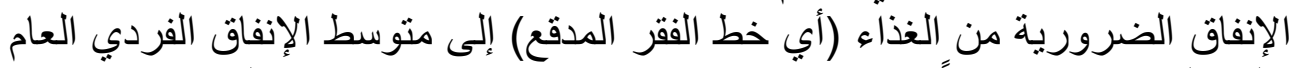
على الغذاء هي تقريباً

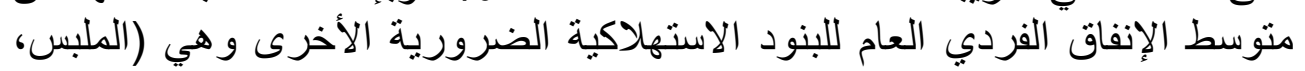


السكن، الأثناث والمفروشات، الطاقة، التعليم، الخدمات الصحية، خدمات النقل)

(*) (*) $117, \wedge 9=$ APL2 نحصل على:

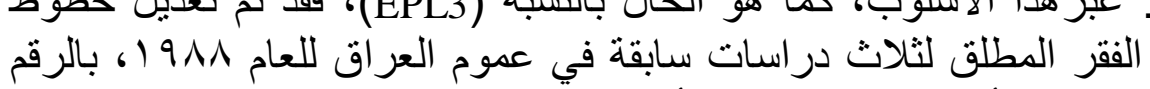

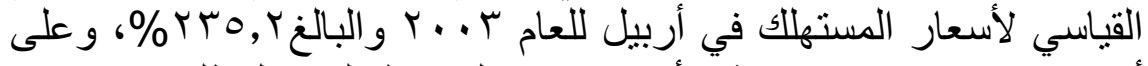

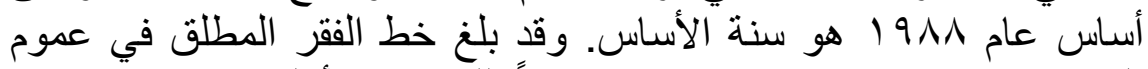

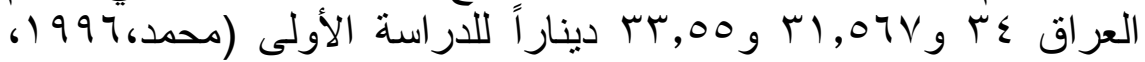

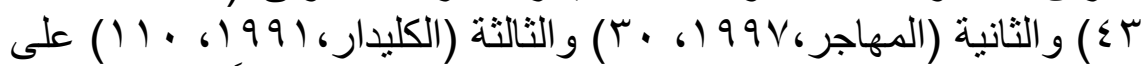

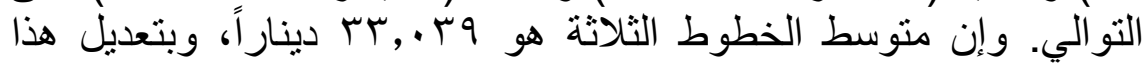

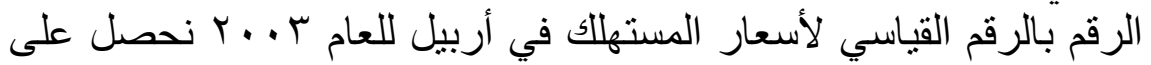

$$
\begin{aligned}
& \text { لوينار اً شهرياً. }
\end{aligned}
$$

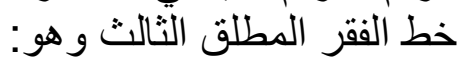

(APL 4): وفقاً لهذا الأسلوب يتم تحديد خط الفقر المطلق بإحتساب متوسط حصة الفالة

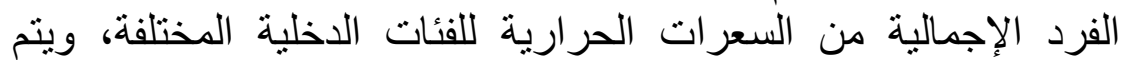

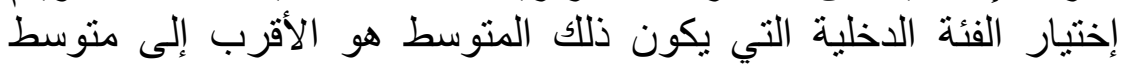

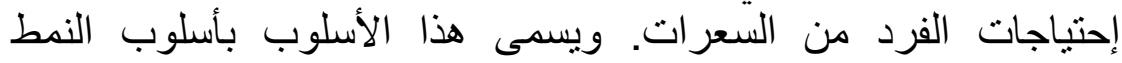

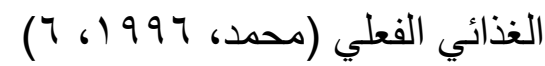

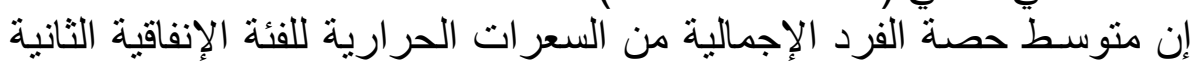

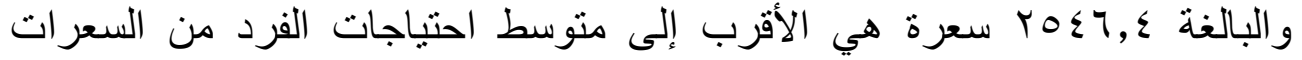

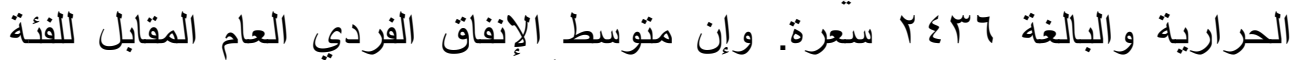

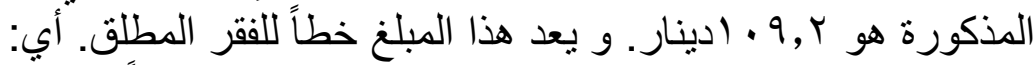
9, 9 = APL 4

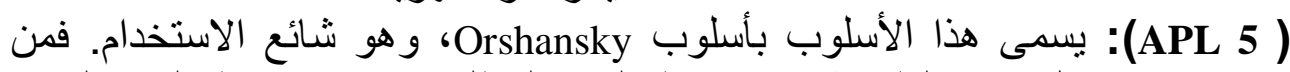

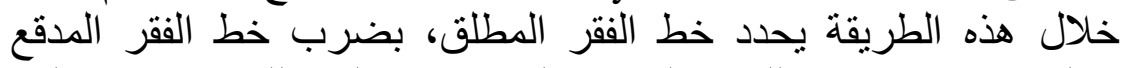
بمقلوب نسبة الإنفاق للبنود الغذائية إلى الإنفاق العام للفئة الإنفاقية التئي تقع فيها العائلة الواقعة عند حد خط الفقر المدقع (Atkinson, 1975, 187) ويمكن تحديد خط الفقر المطلق بهذا هذا الأسلوب بالصيغة الصغ الآتية:

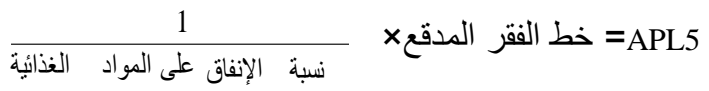

$$
\begin{aligned}
& \text { إر } 99, \mu \wedge=\frac{1}{., 70} \times 7 \varepsilon, 7
\end{aligned}
$$

(*) متوسطات الإنفاق الفردي الثهري لجميع البنود الانفاقية مدرجة في الملحق ب. 


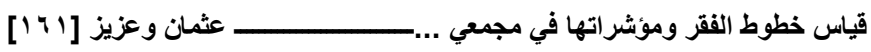

إذ إن: 10, · هي نسبة الإنفاق على المواد الغذائية للفئة الثانية (التي تقع فيها

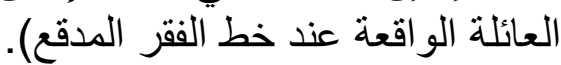

7, ؟ 7 هي متوسط الخطوط الثلاثة للفقر المدقع للار اسة الحالية.

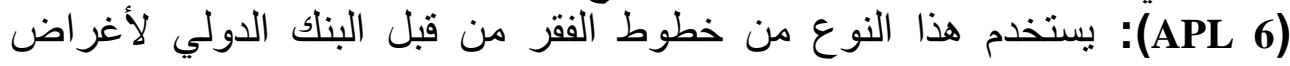
المقارنات الدولية. فعلى وفق هذه الطريقة يحدد خط الفقر المطلق في

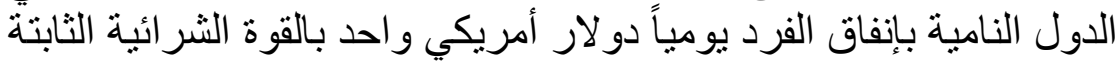

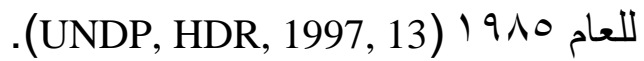

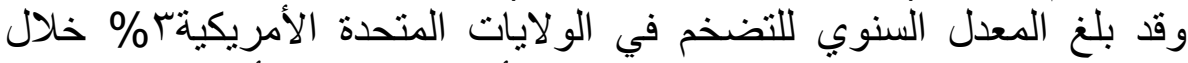

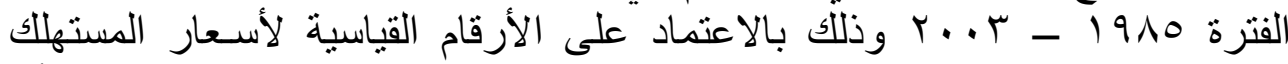

(www.imf.org) (CPI)

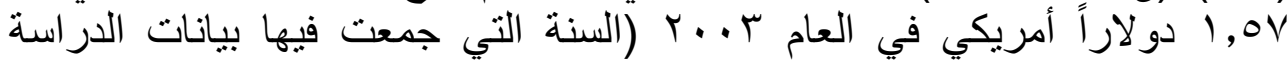

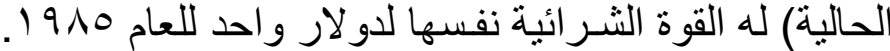

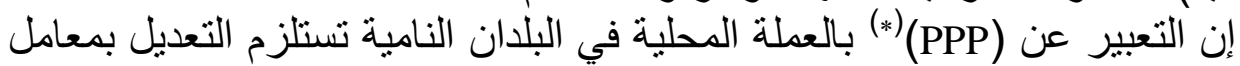

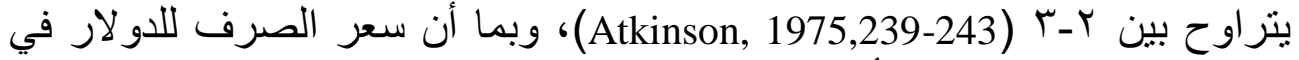

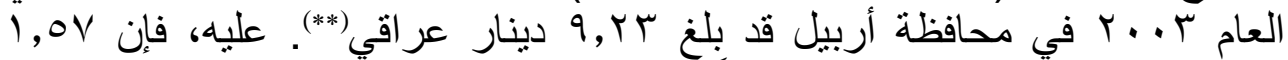

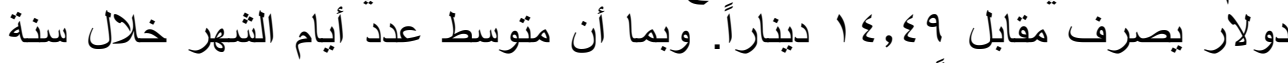

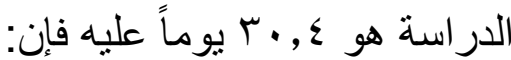

ا لـ الرفم

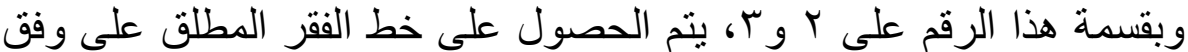

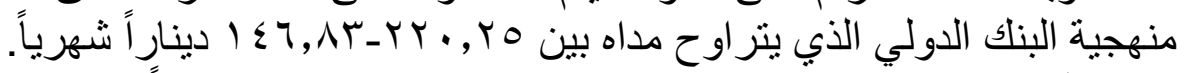
r. خط الفقر النسبي (Relative Poverty Line (RP): نظراً لتغير متطلبات الحياة، لا يمكن القبول بتعريف مطلق للفقر (2, George,1980). كما أن مفهوم الفقر يختلف باختلاف التركيب الاجتماعي وباختلاف مراحل الاف النمو الاقتصادي

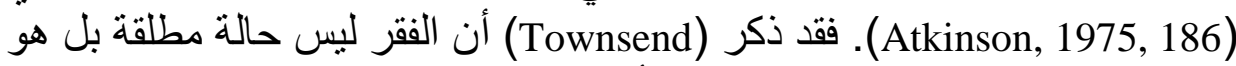

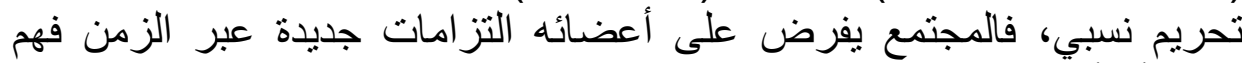

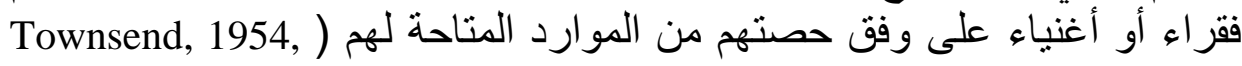
.(130-137

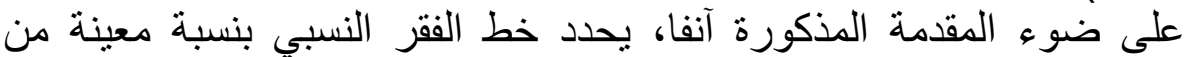

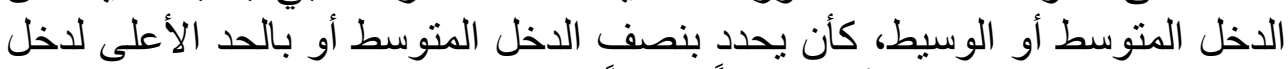

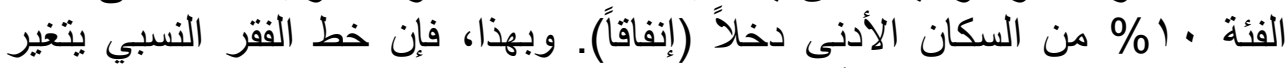

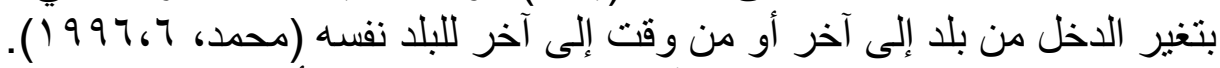

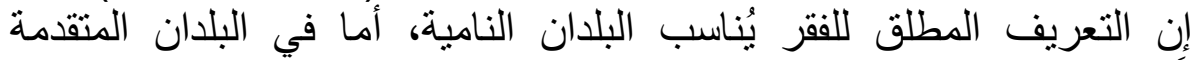

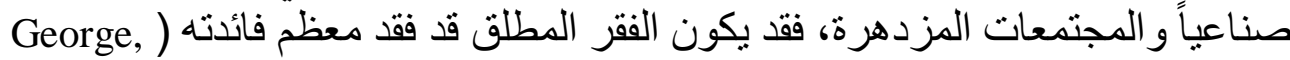

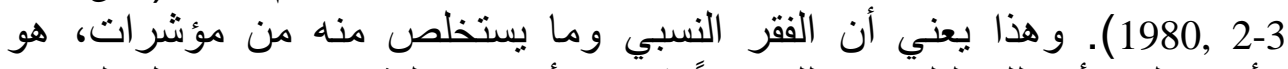
الأنسب لها لأن تلك البلدان تمتلك عادةً شبكات أمان مختلفة تضمن حصول السـكان

${ }^{(*)} \mathrm{PPP}=$ Purchasing Power Parity.

( أخذت المعلومات من سجلات المتعاملين بالعملات الأجنبية. 
كافة تقريباً على الحد الأدنى من الاحتياجات الأساسية (الطاهر، 999 (19 V • ( ). لذا،

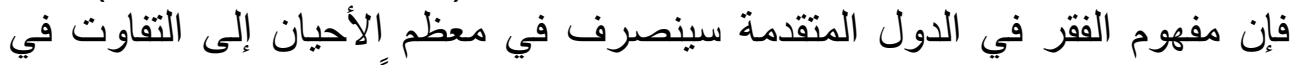

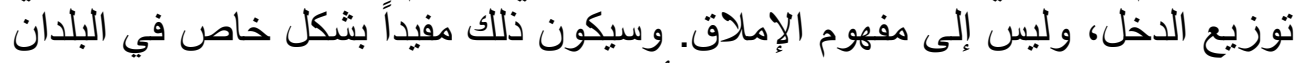

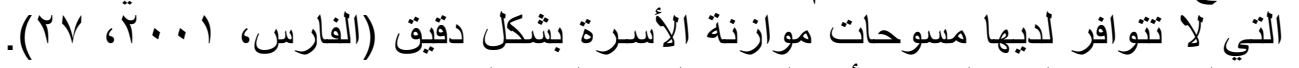

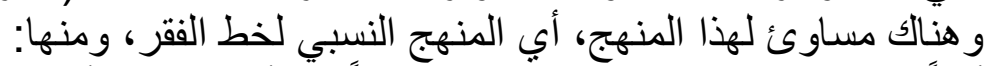

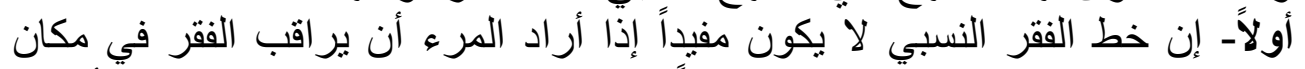

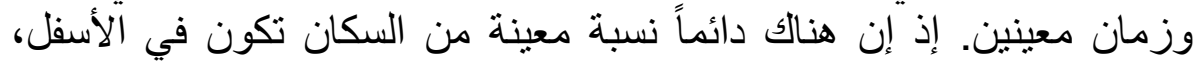

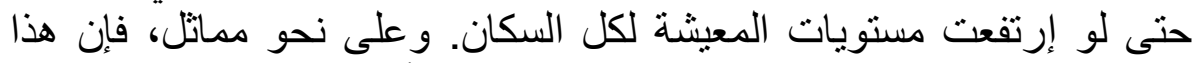

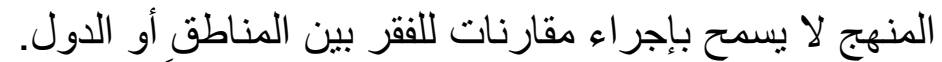

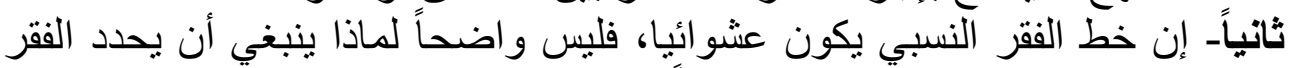

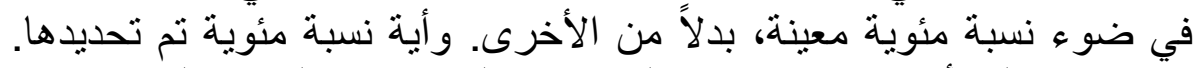

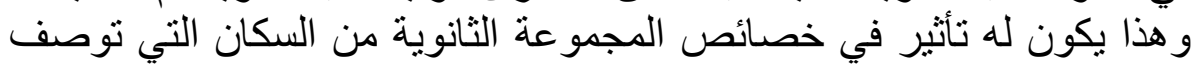
بالمجمو عة الفقيرة (www.undp.org). إن المفهوم النسبي للفقر يمكن تحويله إلى نقد بطر ائق عديدة. و الدراسة الحالية

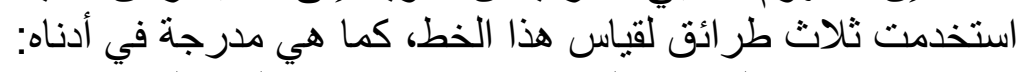

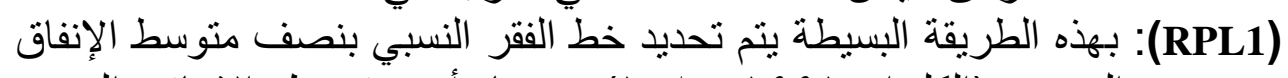

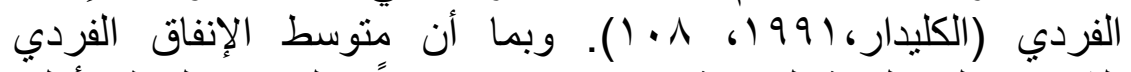

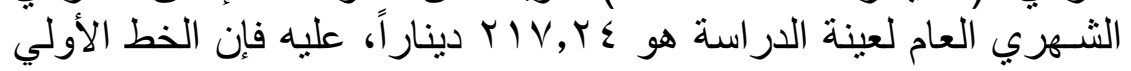
للفقر النسبي هو:

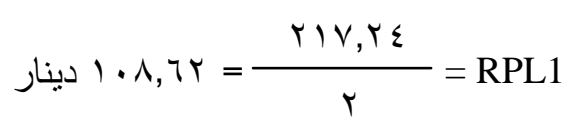

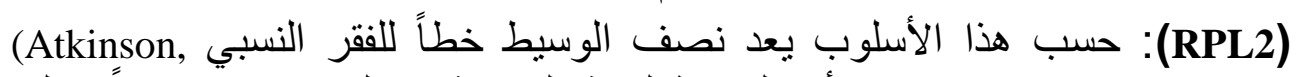

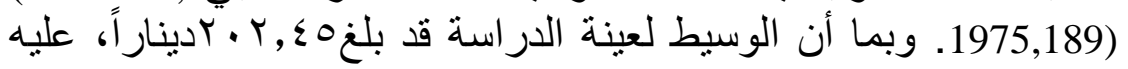

$$
\begin{aligned}
& \text { الإع = RPL2 } \\
& \text { فإن الخط الثاني للفقر النسبي هو: الوسيط لعنية }
\end{aligned}
$$

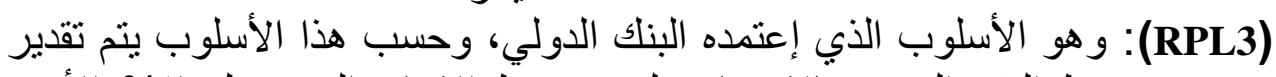

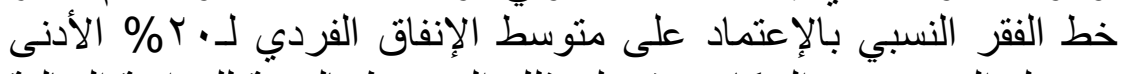

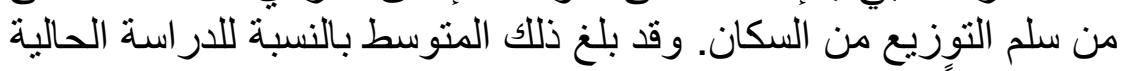

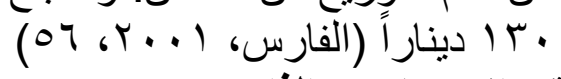

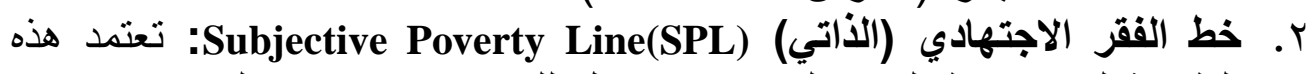

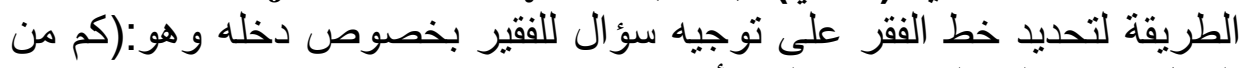

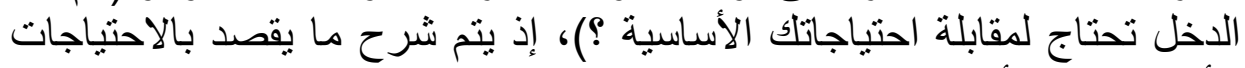

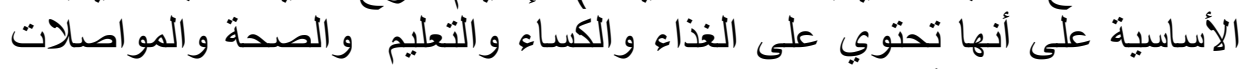

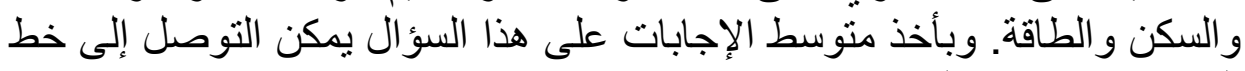
الفقر الاجتهادي (علي، ع ؛، الانترنت). 


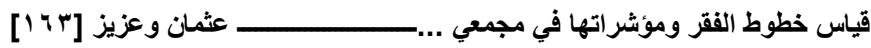

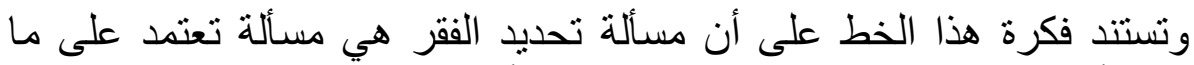

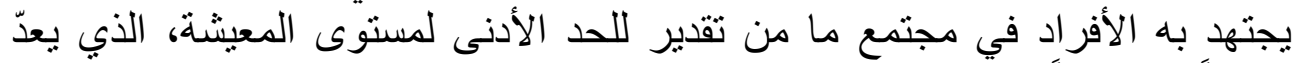

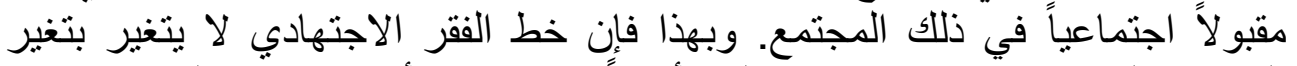

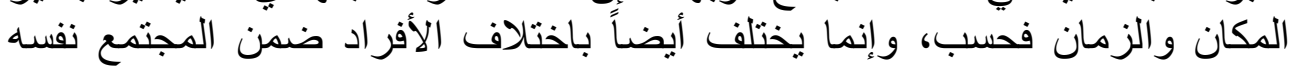

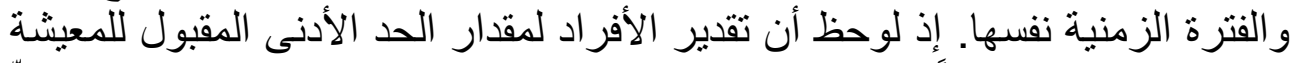

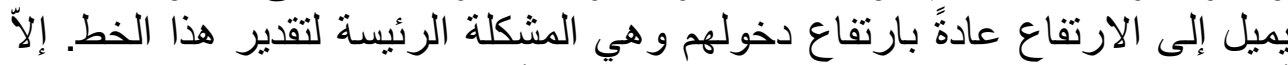

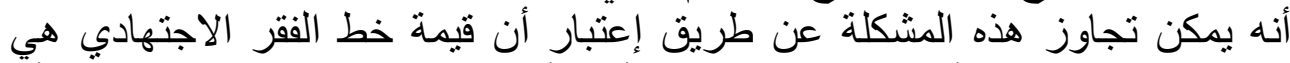

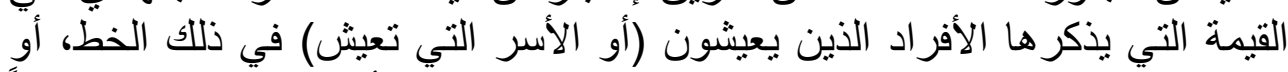

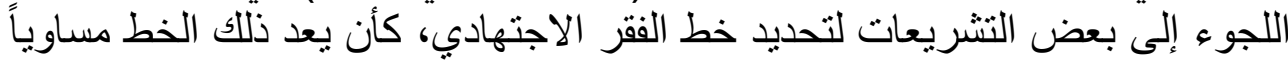

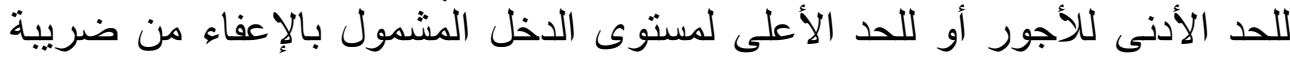

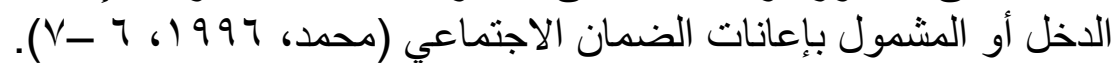

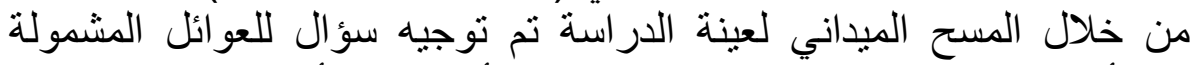

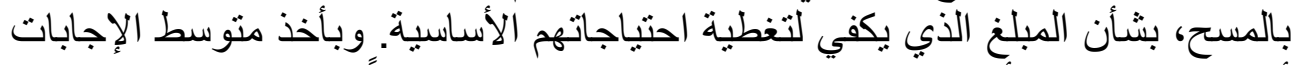

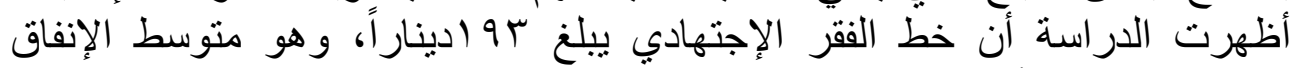
r =SPL 19 دينارً خط الفقر الاجتهادي.

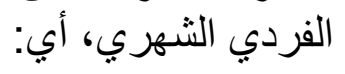

\section{ثانياً- مؤشرات الفقر (Poverty Indices)}

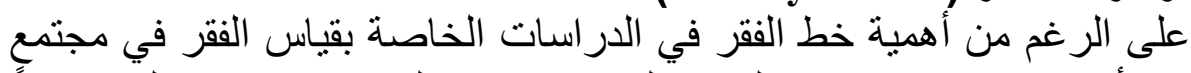

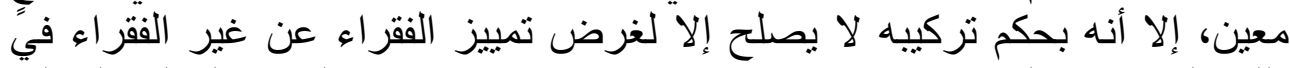

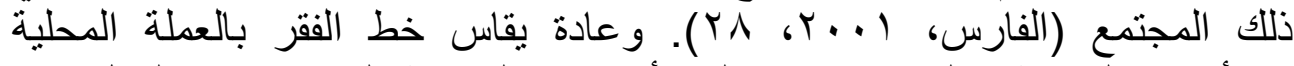

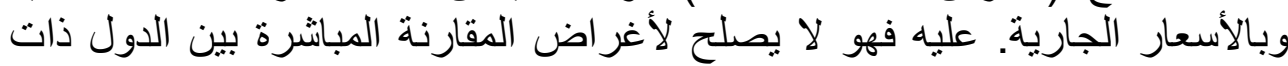

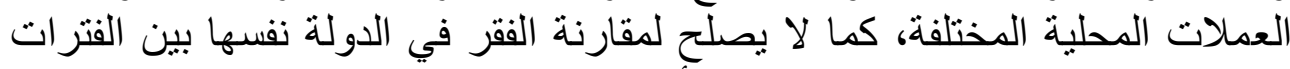

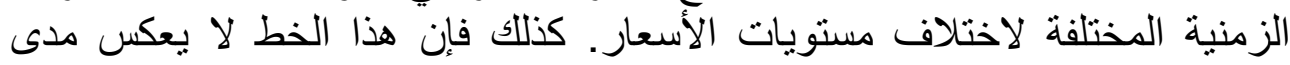

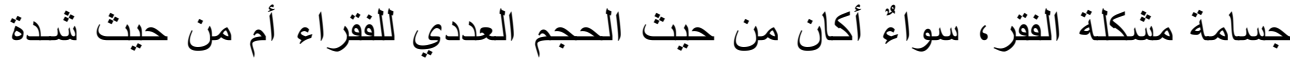

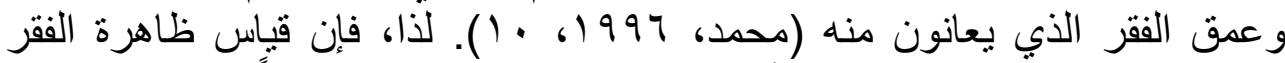

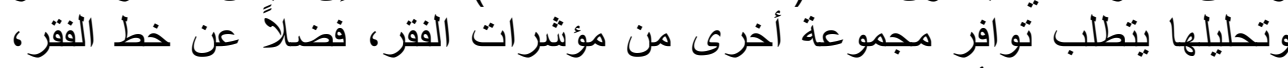
وذللك للاطلاع على أبعاد الفقر الممكنة.

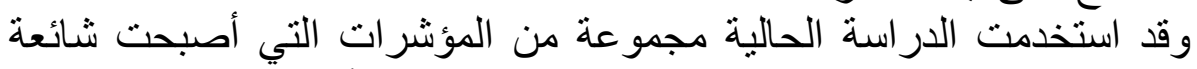

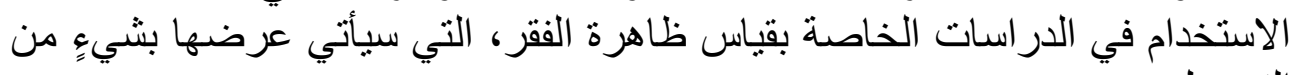

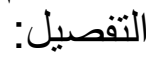
ا ـ مؤشر عدد الرؤوس (Head-Count Index): وهو أكثر مؤشرات قياس الفقر

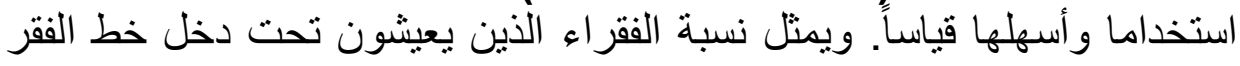

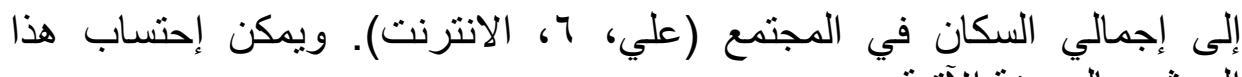

$$
\mathbf{H}=\mathbf{q} / \mathbf{n} \times 100
$$

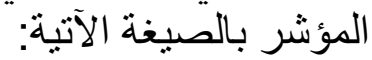

حيث إن: H = نسبة السكان الفقراء، نسبة مئوية.

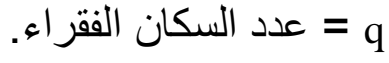




\section{n}

كما ويمكن قياس هذا المؤشر على مستوى الأسرة بالصيغة الآتية (المعدوري،

$$
\mathrm{R}_{1}=\mathrm{N}_{1} / \mathrm{S}_{1} \times 100
$$

$$
\text { حيث إن: R = R = نسبة الأسر الفقبرة. }
$$

$$
\text { = N = }=\mathrm{N}_{1}
$$

$$
\text { = S } \text { S }_{1}
$$

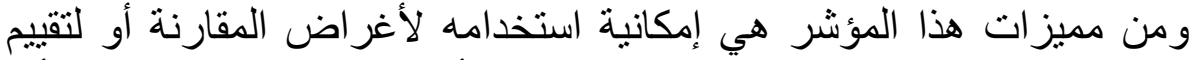

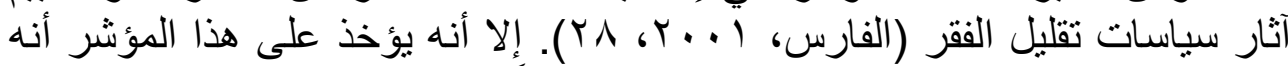

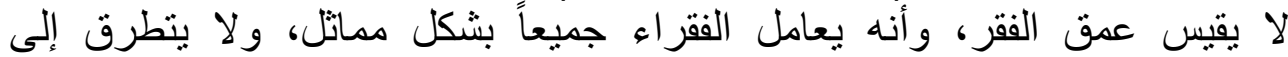

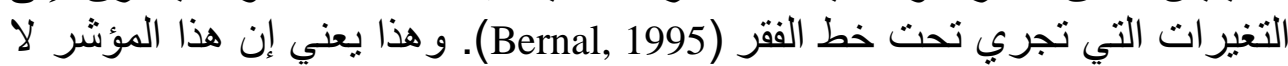

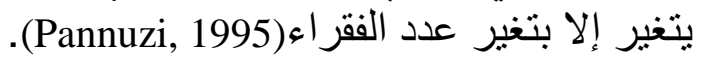
r. مؤشر فجوة الفقر (Poverty Gap Index): يحدد هذا المؤشر مقدار الدخل

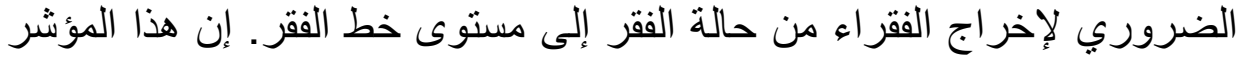

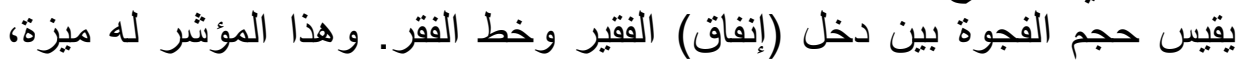

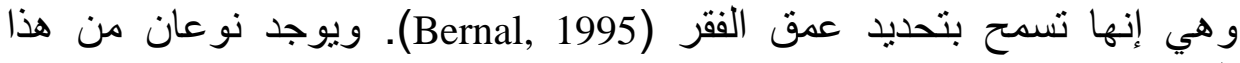
المؤشر ، وهما: أ. الفجوة المطلقة (الإجمالية) للفقر Absolute Poverty Gap: وهو يساوي إجمالي الري

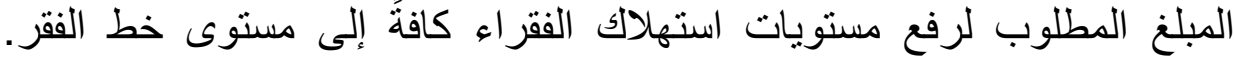

$$
\mathrm{TPG}=\mathrm{q}(\mathrm{z}-\mathrm{yp})
$$

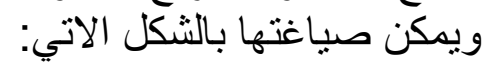

$$
\text { حيث إن: }=\text { TPG الفجوة الإجمالية للفقر. }=\text { z }
$$

ب. فجوة الفقر النسبية (Relative Poverty Gap): ويمكن احتسابها بالصيغة الآتية

$$
\mathbf{I}=(\mathbf{z}-\mathbf{y p} / \mathbf{z}) \times 100
$$

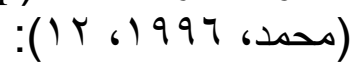

حيث أن: I I الفجوة النسبية للفقر. وتفسر فجوة الفقر النسبية بأنها تعبر عن مقدار إنخفاض منوسط إنفاق الفقير

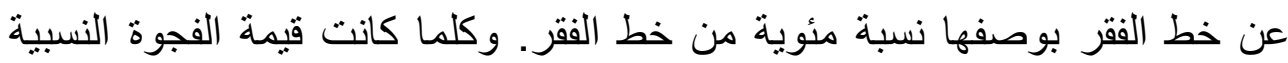

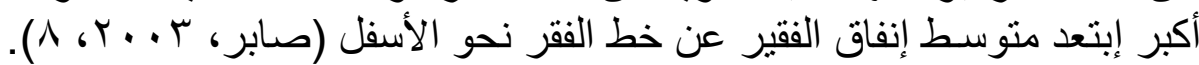

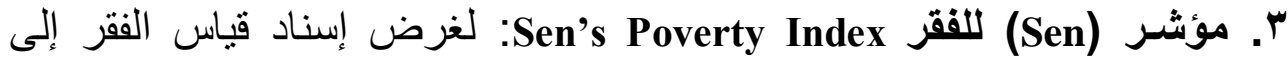
مرتكزات منطقية وموضو عية، إقترح البروفيسور (Amartya Sen) بديهينين

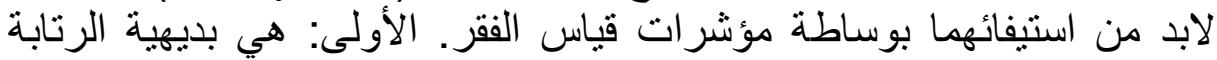
Monotonicity Axiom)

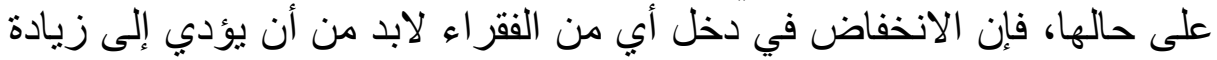

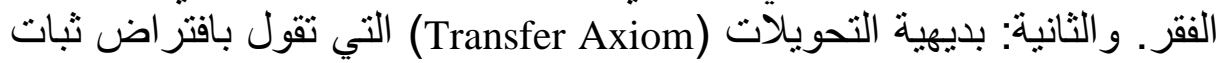


قياس خطوط الفقر ومؤشر اتها في مجمعي .... _.

كل الأشياء الأخرى على حالها، فإن تحويلاً للاخل من أحد الفقر اء إلى فرد آخر

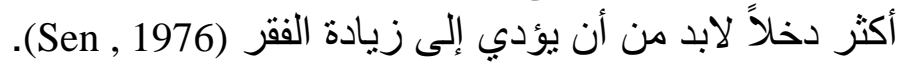

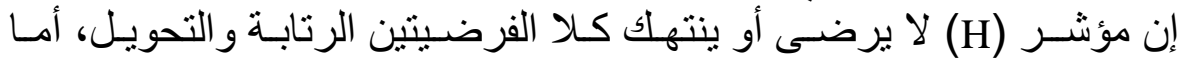

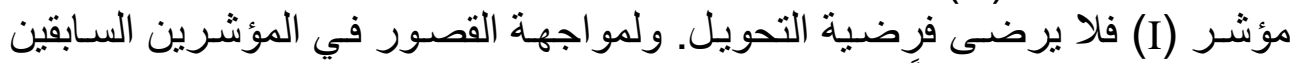

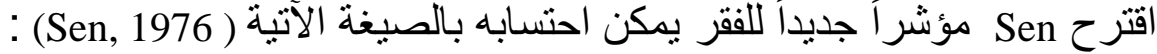
Ps $=\mathrm{H}[\mathrm{I}+(1-\mathrm{I}) \mathrm{G}]$

$$
\begin{aligned}
& \text { حيث إن: Ps = مؤشر Sen للفقر. } \\
& \text { = I } \\
& \text { = H } \\
& \text { = G }
\end{aligned}
$$

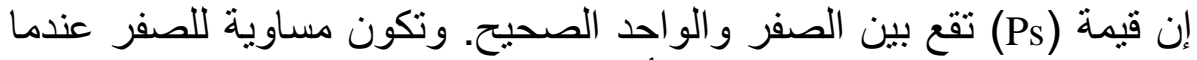
يكون متوسط الإنفاق الثهري لكن فين فرد أكبر من خط الفر. في حين قيمته تكون

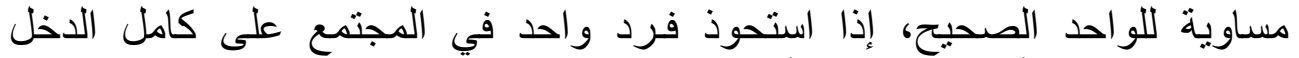

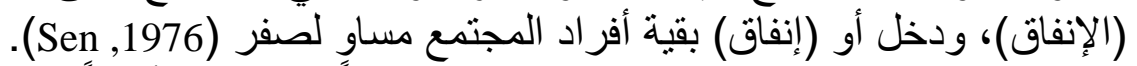

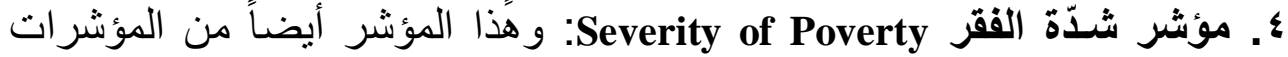

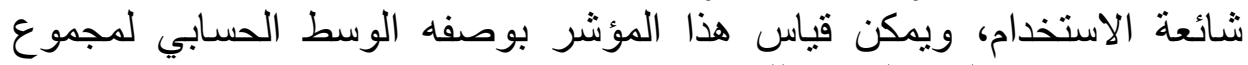

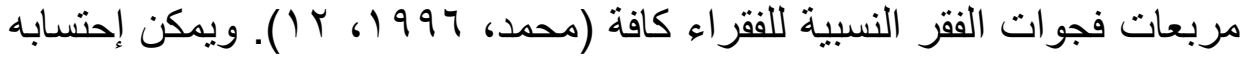

$$
\mathrm{PFGT}=\frac{\mathbf{1}}{\mathrm{n}} \sum_{\mathrm{p}=\mathbf{1}}^{\mathrm{q}}\left(\frac{\mathrm{z}-\mathrm{yp}}{\mathrm{z}}\right)^{2} \times \mathbf{1 0 0}
$$

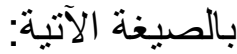

حيث إن : PFGT = مؤشر شدّة الفقر.

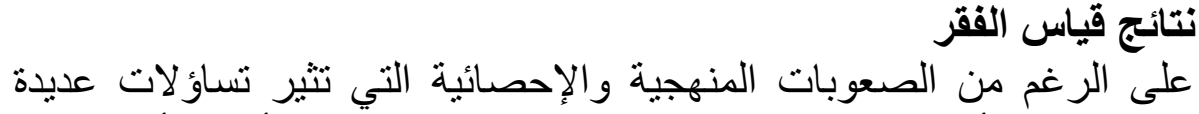

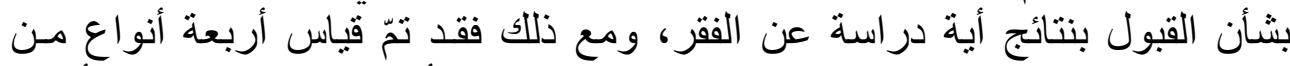

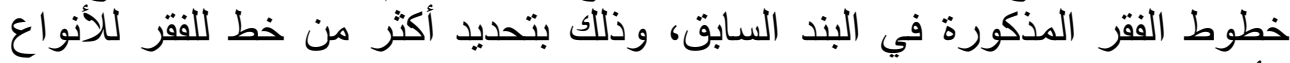

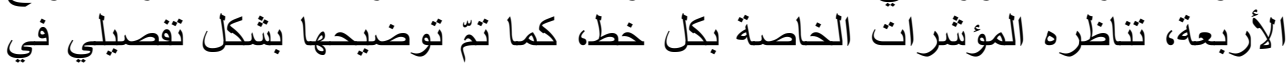

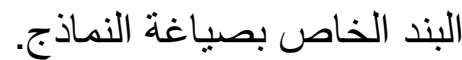

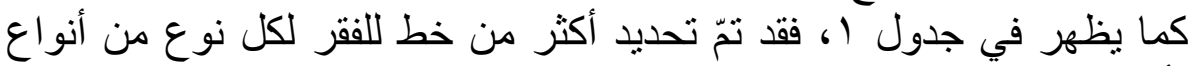

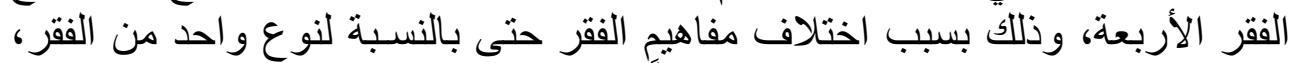

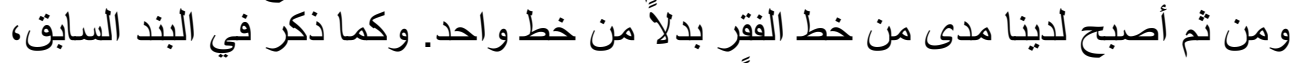

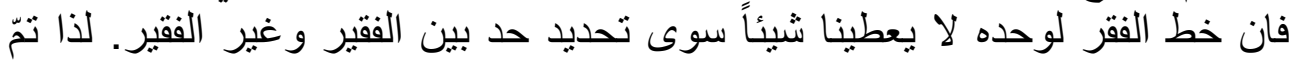

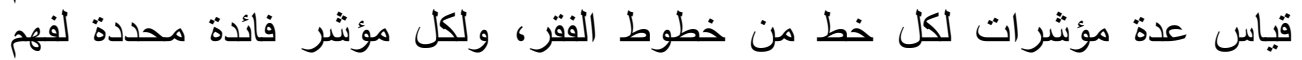

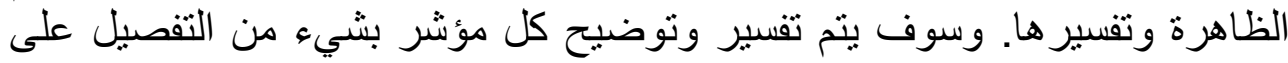

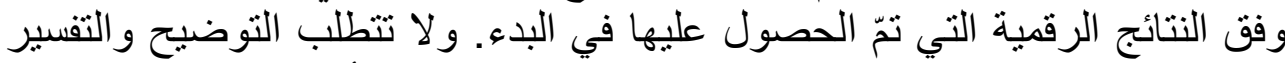

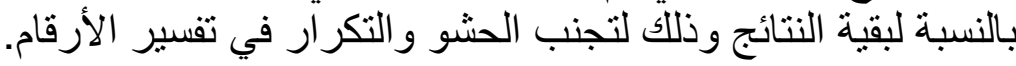




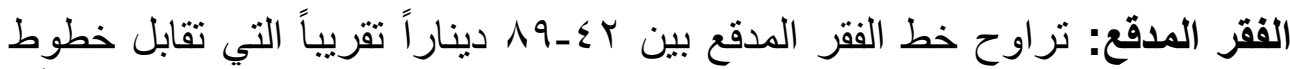

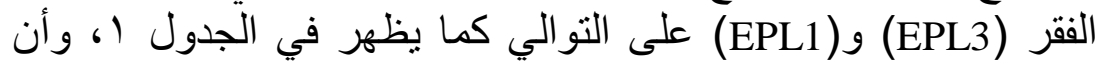

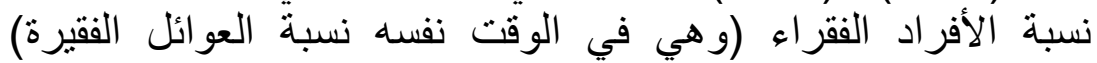

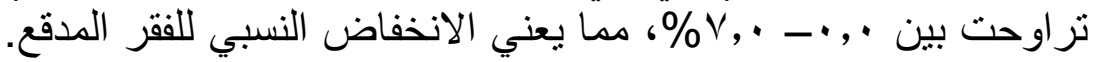

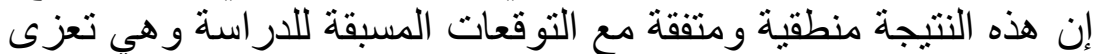

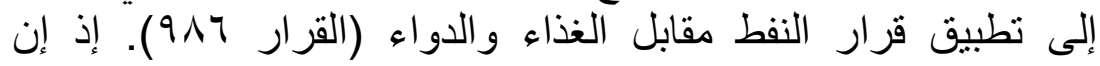

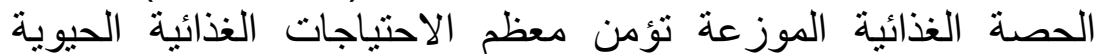

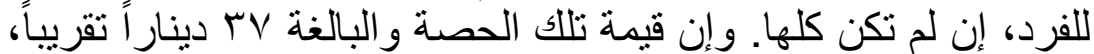

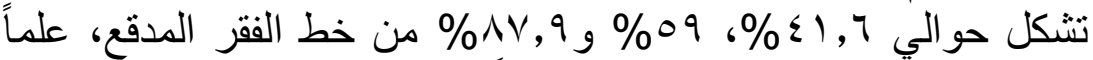

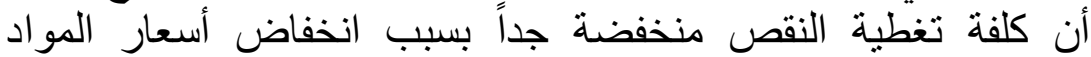
الغذائية في محافظة أربيل. أما بالنسبة للفجوة النسبية فهي تتراولة اوح بين

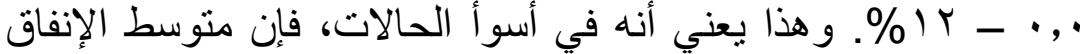

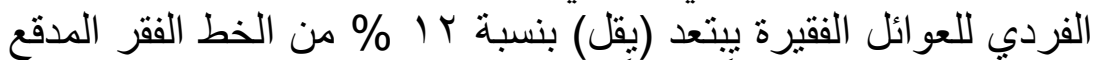

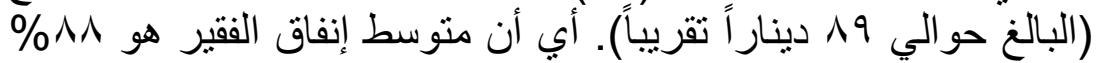

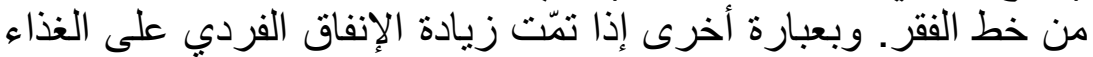

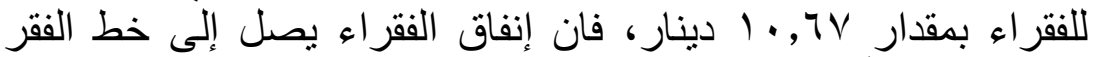

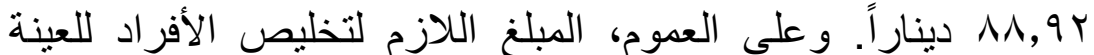

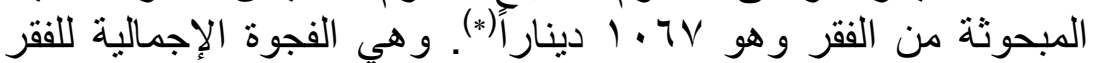

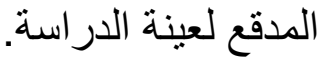

\begin{tabular}{|c|c|c|c|c|c|c|c|c|}
\hline \multicolumn{9}{|c|}{ الجدول 1} \\
\hline \multicolumn{6}{|c|}{ المؤشـــــــرات المناظرة لكل خط } & \multicolumn{3}{|c|}{ خطوط الفقر } \\
\hline $\begin{array}{c}\text { مؤشرة } \\
\text { الفقر)(\%GT } \\
\text { PFGT }\end{array}$ & $\begin{array}{l}\text { مؤشر } \\
\text { SEN } \\
\text { (PS) }\end{array}$ & اللفبنية & 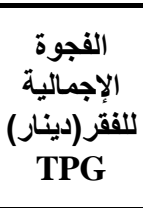 & $\begin{array}{c}\text { الأفراد } \\
\text { الفقراء } \\
\text { (\%) } \\
\text { (H) }\end{array}$ & $\begin{array}{c}\text { الأفراد } \\
\text { الفقراء } \\
\text { (q) }\end{array}$ & مقدار الخطار) & 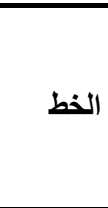 & \\
\hline$\cdot, \cdot 7$ & $\cdot, \cdot 1 \pi \leq$ & IT & $1.7 V$ & $\vee, \cdot$ & $1 \cdots$ & $\wedge \wedge, 9 r$ & EPL1 & \\
\hline$\cdot, \cdots V$ & $\cdot, \cdots 17$ & $\overline{1 \cdot, r}$ & $17 \cdot, 70$ & $1, \mathrm{~V}$ & TO & $7 \pi$ & EPL2 & الفقر \\
\hline$\cdot, \cdot$ & $\cdot, \cdot$ & $\cdot, \cdot$ & $\cdot, \cdot$ & $\cdot, \cdot$ & $\cdot, \cdot$ & $\varepsilon r, \cdot V V$ & EPL3 & \\
\hline$\cdot, \cdot 1 \leq$ & $\cdot, \ldots V r$ & Ir, & $V 11, V V$ & r,^ & $0 \leqslant$ & $1 \cdot \wedge, \cdot \varepsilon$ & $\begin{array}{l}\text { APL1 } \\
\text { a }\end{array}$ & \\
\hline$\cdot, \cdot \varepsilon r$ & $\cdot, \cdot$, r & $1 \wedge, 0$ & $r \cdot \leqslant q, 70$ & $\wedge, 9$ & ITV & Irq,^ & $\begin{array}{l}\text { APL1 } \\
b\end{array}$ & المطلق \\
\hline$\cdot, \cdot Y Y$ & $\cdot, \cdot 11$ & 14 & $1 \pi \cdot T, \wedge \pi$ & 7 & $\overline{\Lambda T}$ & 117,19 & APL2 & \\
\hline$\cdot, \cdots 1 \varepsilon$ & $\cdot, \cdots r$ & 0,0 & $r \varepsilon, 19$ & $\cdot, 7$ & $\Lambda$ & $V \vee, V I$ & APL3 & \\
\hline
\end{tabular}

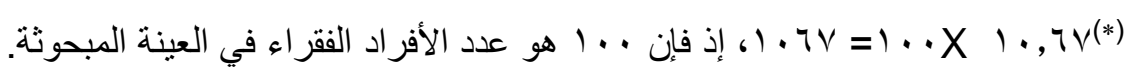




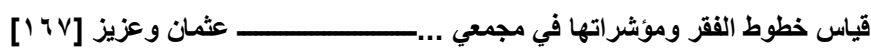

\begin{tabular}{|c|c|c|c|c|c|c|c|c|}
\hline., .10 & $\cdot, \ldots \vee 0$ & $1 \pi, r$ & $\checkmark \vee q, \Lambda$ & $r, \Lambda$ & $0 \xi$ & $1.9, \varepsilon$ & APL4 & \\
\hline$\cdot, \ldots 9$ & $\overline{\theta, \ldots r}$ & $\mathrm{~V}, 0$ & $1 \leqslant 9,1$ & $1, \varepsilon$ & $r$. & $99, r \wedge$ & APL5 & \\
\hline$\cdot, \mathrm{V}$ & $\cdot, 11$ & $r T, O$ & $\Sigma \backslash A V Y, A T$ & $07,\{$ & 1.9 & rr.,YO & $\begin{array}{l}\text { APL6 } \\
\text { a }\end{array}$ & \\
\hline$\cdot, 10$ & •, . TV & $r \cdot, r$ & $\Lambda r \cdot \varepsilon, v$ & 19,0 & rA. & $1 \leqslant 7, \wedge r$ & $\begin{array}{l}\text { APL6 } \\
\text { b }\end{array}$ & \\
\hline$\cdot, \cdot 1 \leqslant$ & $\therefore, \cdots \vee \leqslant$ & $1 Y, 7$ & $V r q$ & $r, \Lambda$ & $0 \leqslant$ & $1 \cdot \Lambda, T Y$ & RPL1 & \multirow{3}{*}{ النسبي } \\
\hline$\cdot, \cdots 91$ & $\cdot, \ldots Y A$ & $9, r$ & rTO, MT & $1, \mathrm{~V}$ & To & $1,1, K \pi$ & RPL2 & \\
\hline 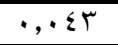 & ., & $1 \wedge, 7$ & $\Gamma 191, V 7$ & $9, Y$ & ITr & $1 \pi$. & RPL3 & \\
\hline$\cdot, \varepsilon$ & $\cdot, 111$ & rr & ro $\leqslant Y$ & $\varepsilon 1,9$ & $7 \ldots$ & 194 & SPL & الاجتهادي \\
\hline
\end{tabular}

المصدر: تم احتساب الجدول بالاعتماد على البيانات الأولية لعينة الدراسة و على وفق الصيخ التي تم توصيفها في البند السابق.

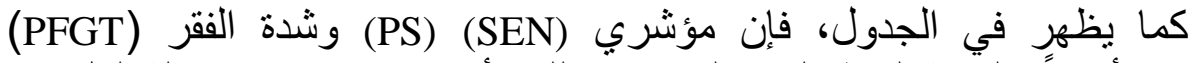

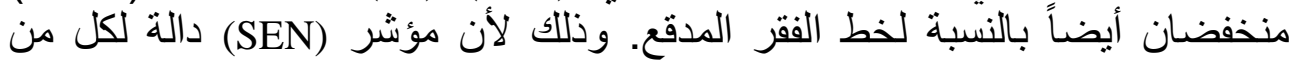

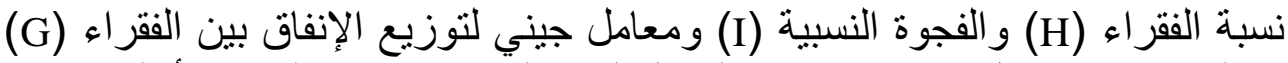

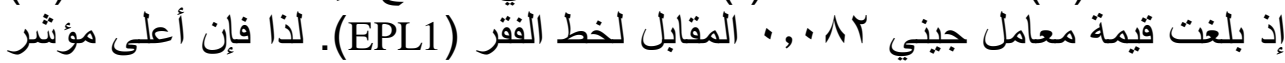
(SEN) متقاربة على ضو اء معامل جيني.

على الرغم من النتائج التي توصلت إلت إليها الدراسة، و وعلى الرغم من إمكانية

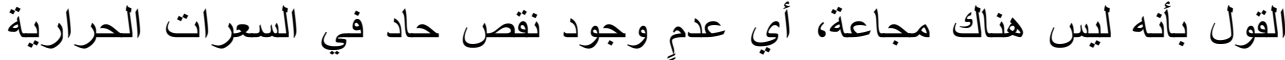

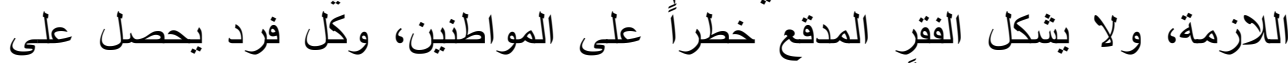

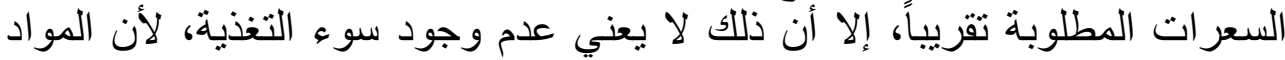

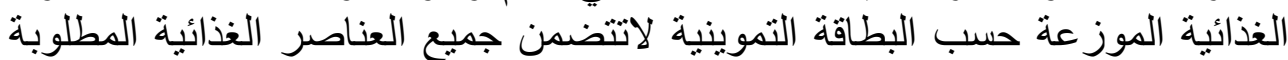

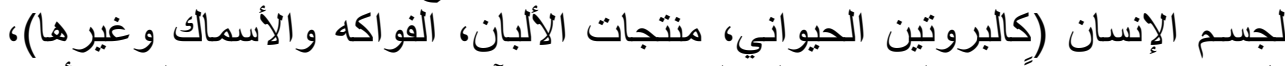

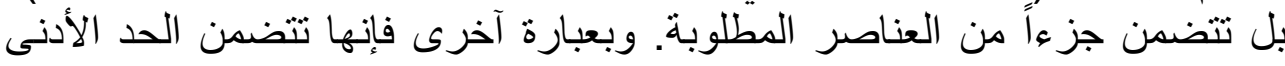

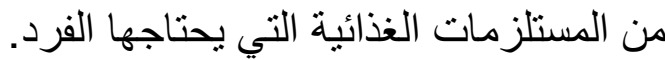

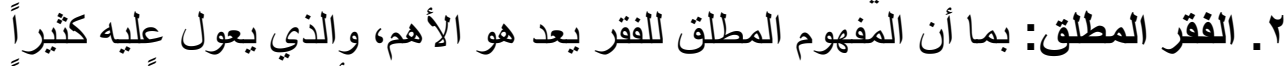

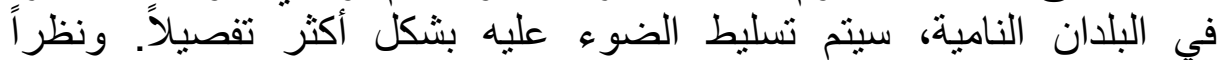

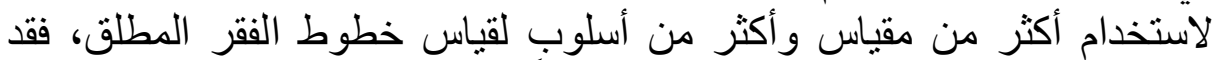

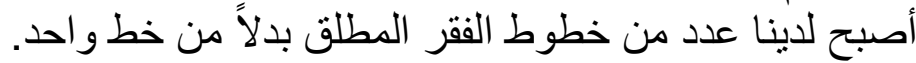

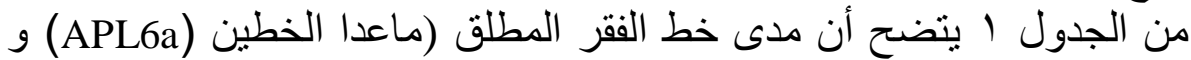

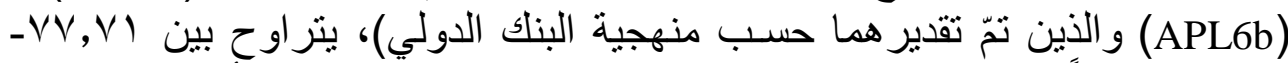

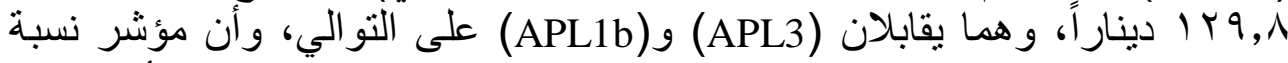

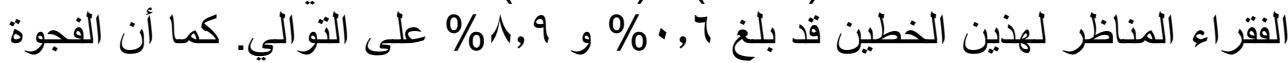

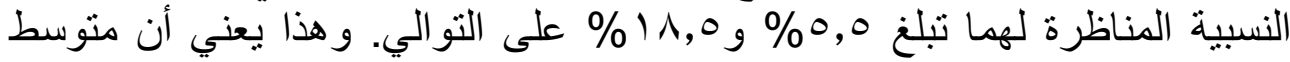

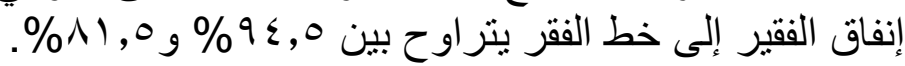

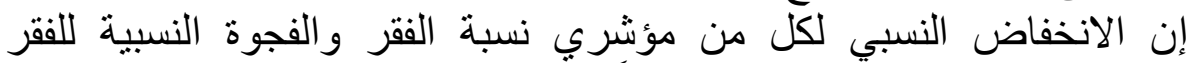

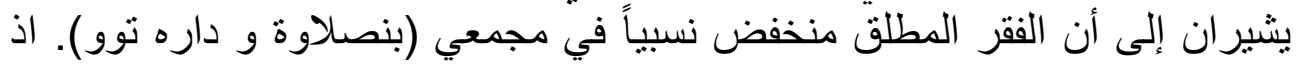


وفقاً لمؤشر الفجوة النسبية يمكن القضاء على الفقر المطلق إذا ما تمّ زيادة الإنفاق

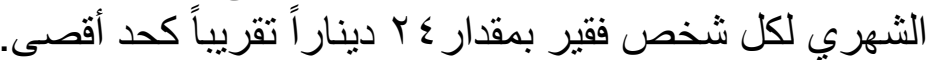

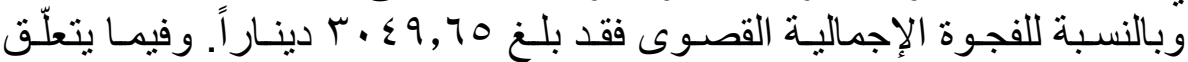

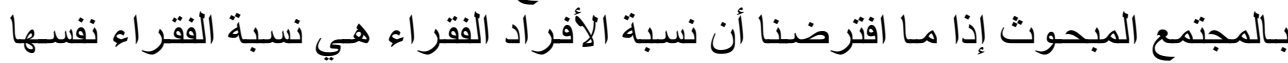

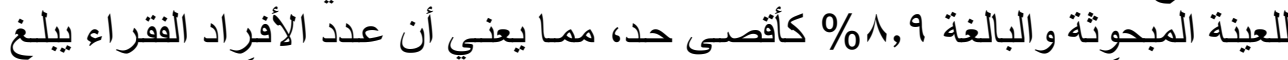

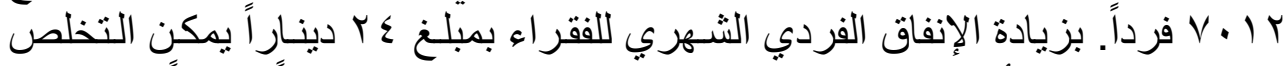

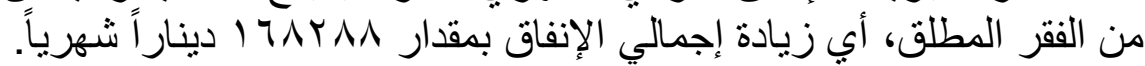

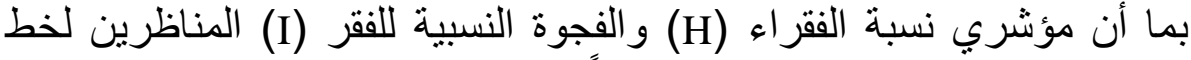

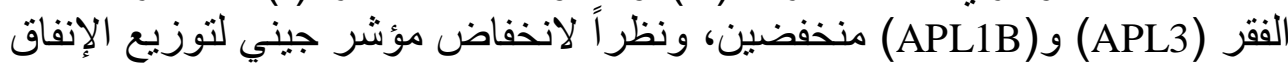

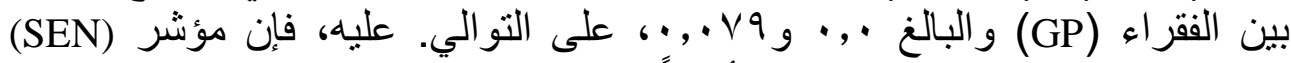

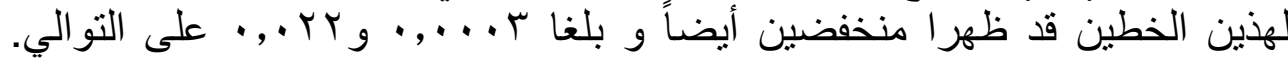

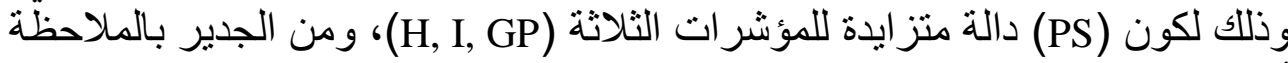

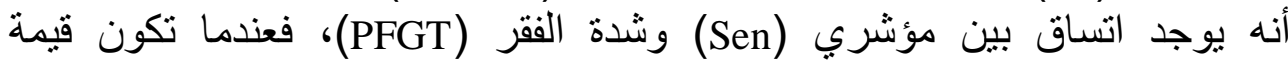

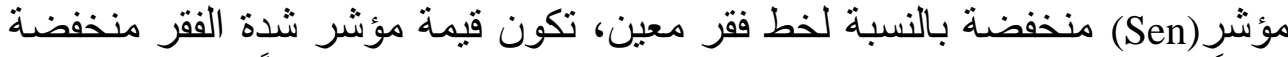

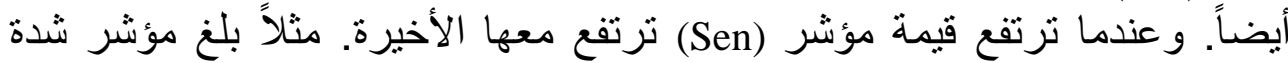

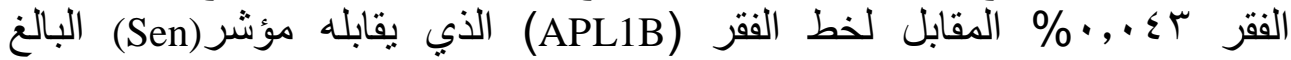

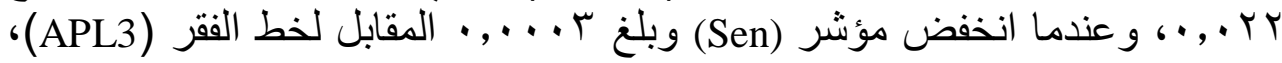

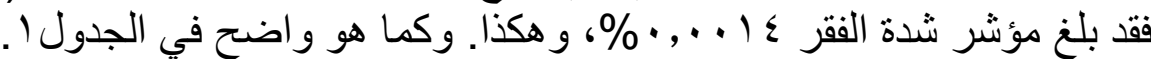

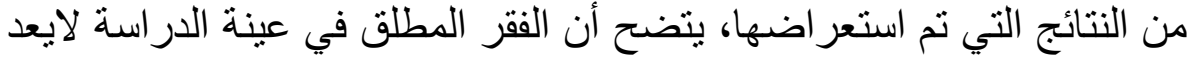

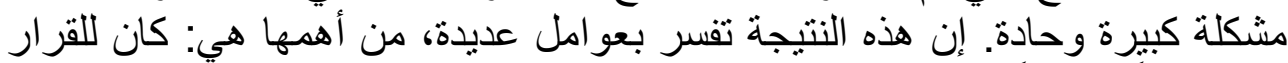

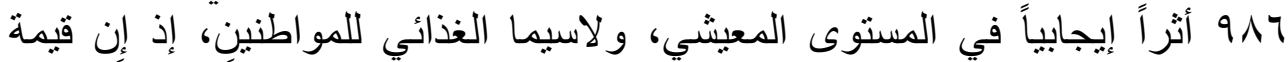

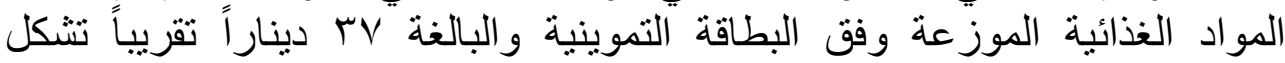

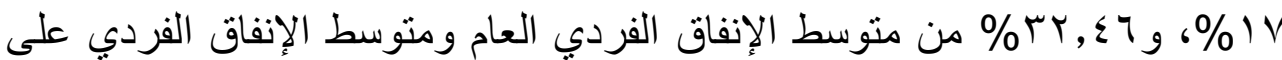

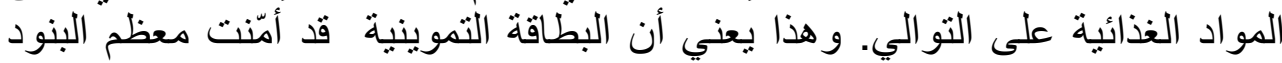

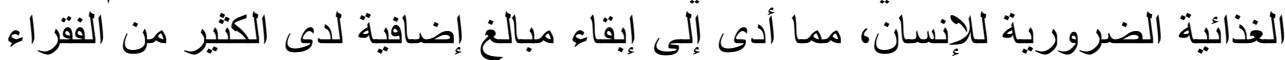

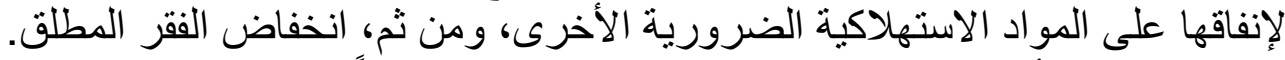

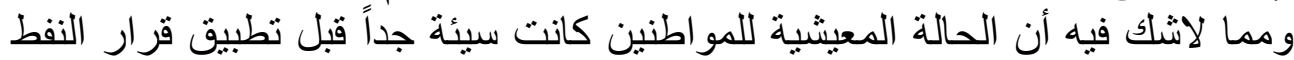
مقابل الغذاء و الدواء.

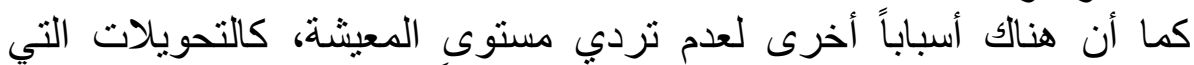

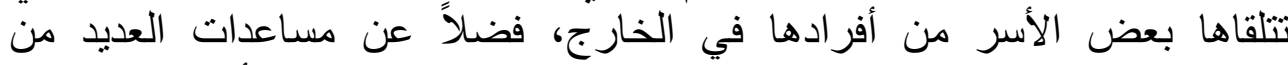

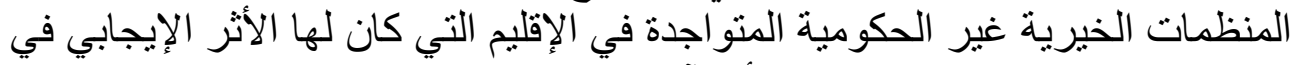

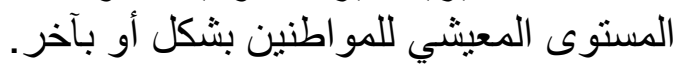

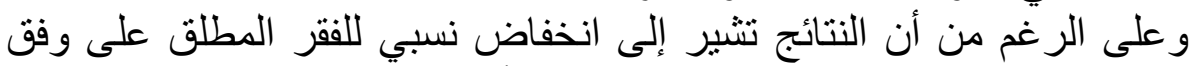

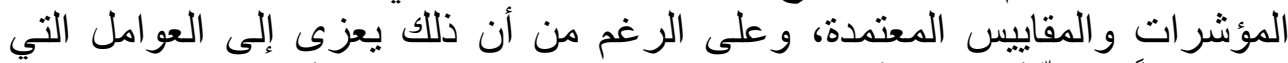

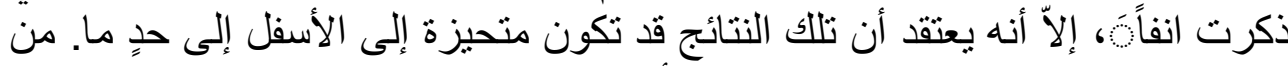

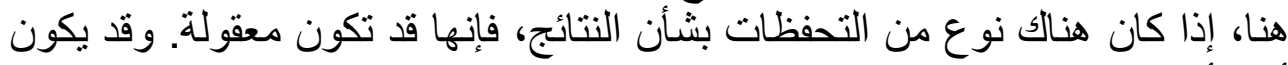

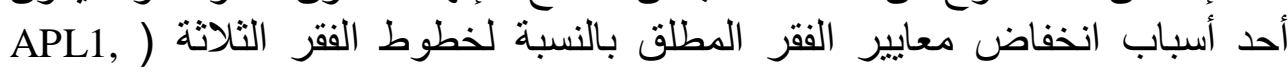




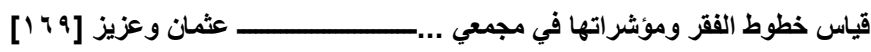

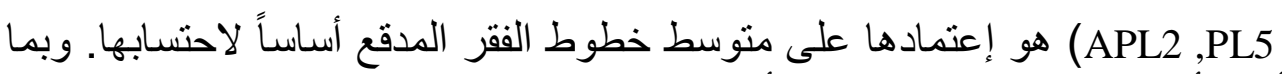

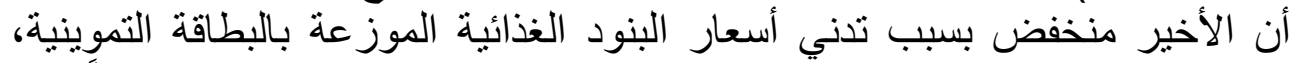

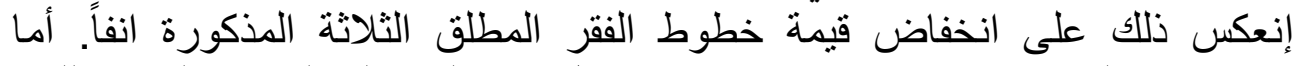

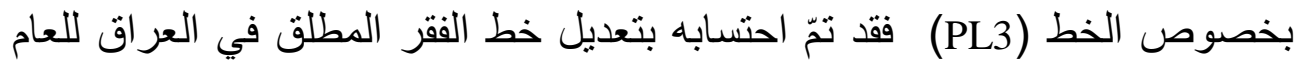
1911 بالرقم القياسي لأسعار المستهلك في أربيل، وقد تكون تلأك الآرقام القياسية للفية

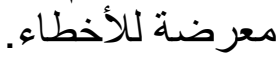

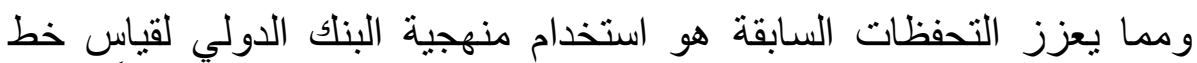

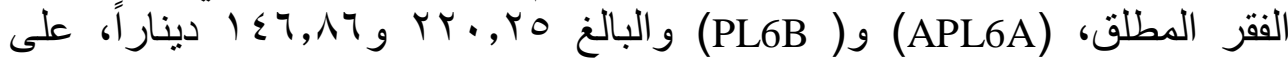

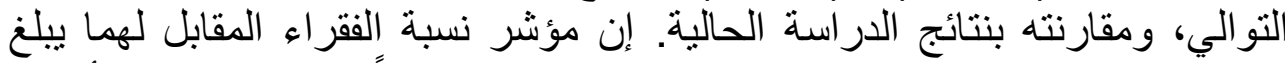

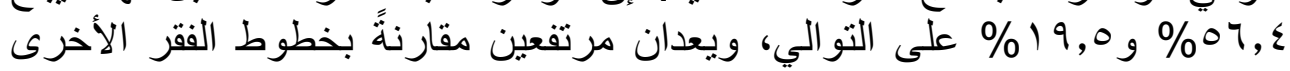

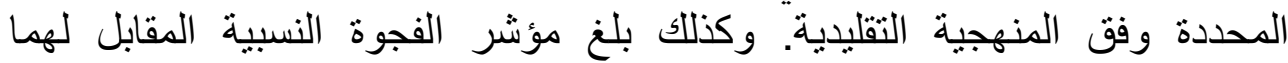

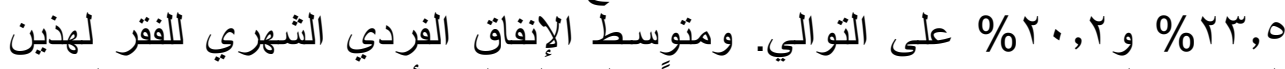

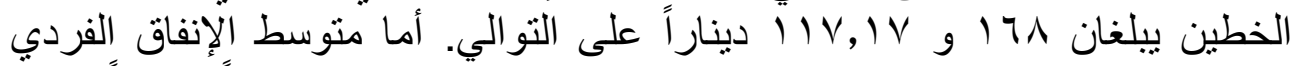

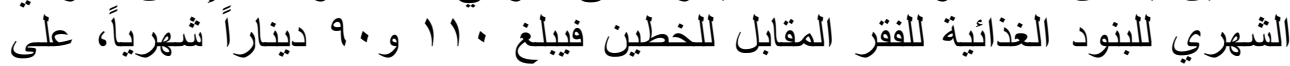

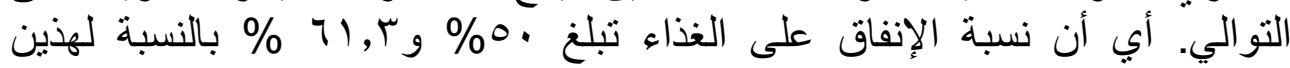

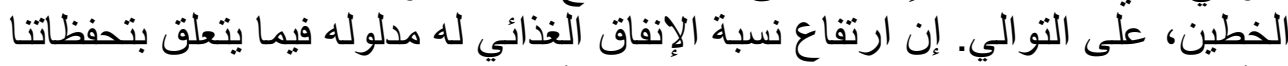

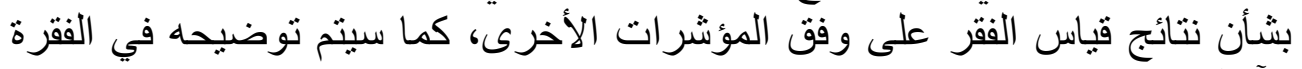
الآتية.

ويمكن الاهتداء إلى مؤشر نسبة الإنفاق الغذائي لتكوين صورة أو فكرة معينة

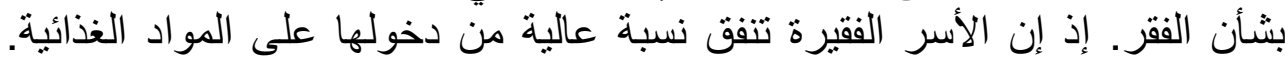

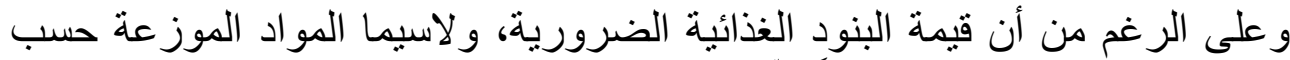

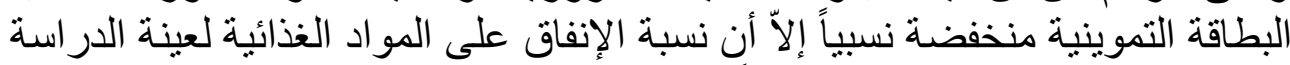

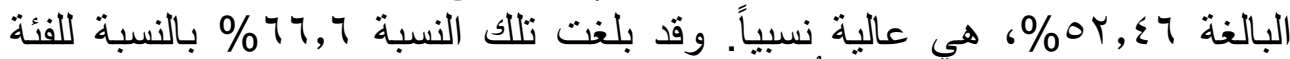

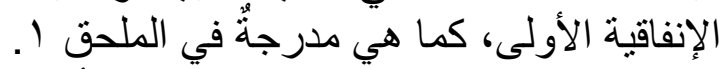

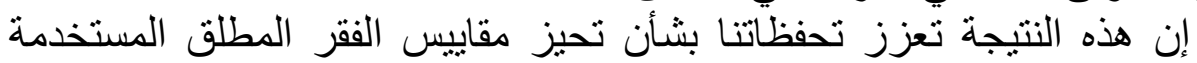

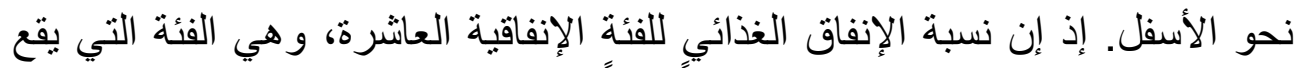

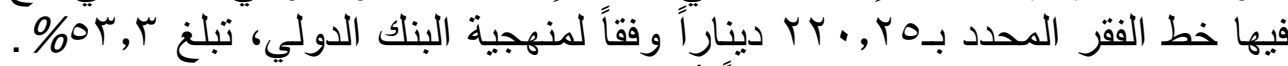

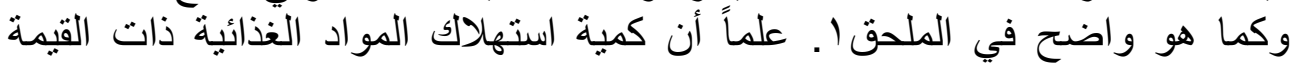

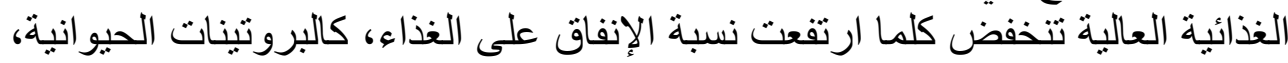

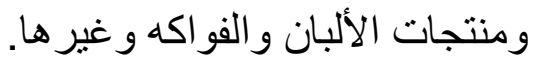

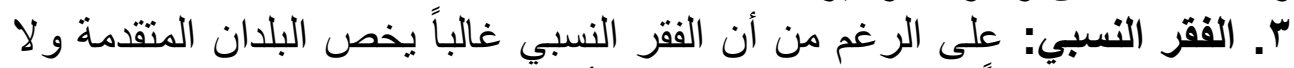

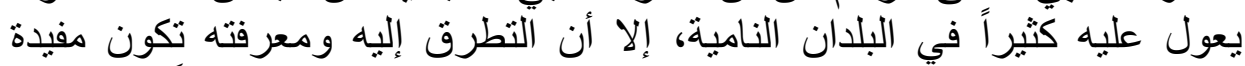

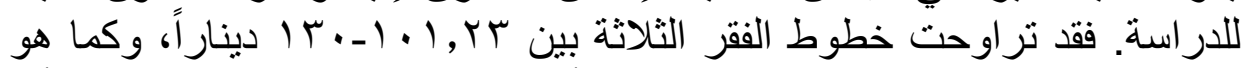

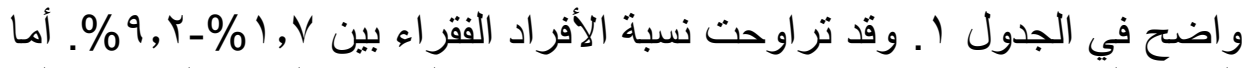

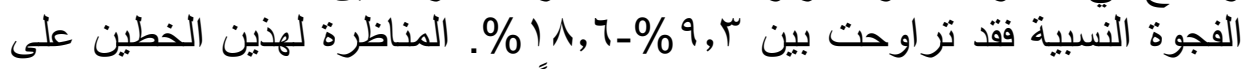

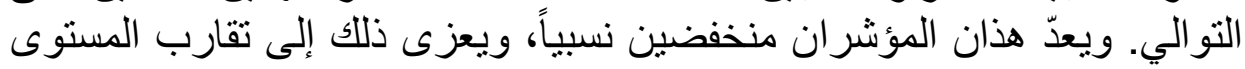


المعيثي لسكان عينة الدراسة إلى حدٍ ما، كما دل على ذلك معامل جيني للتوزيع

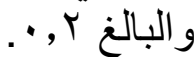

وون الجدير بالملاحظة انخفاض خط الفقر النسبي المحدد بنصف الوسيط

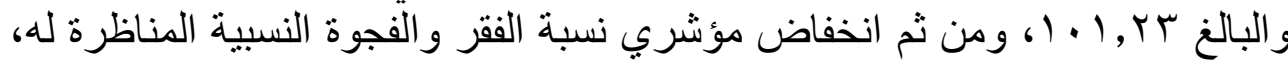

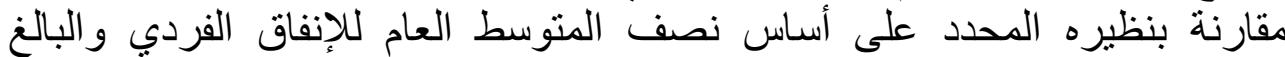

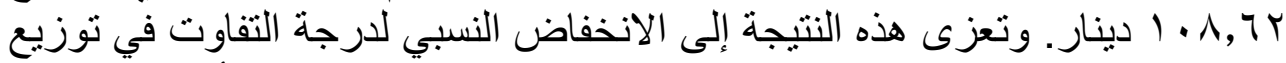

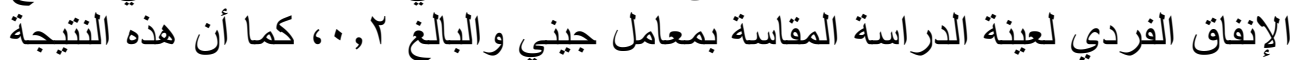

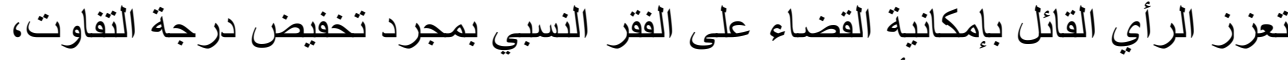

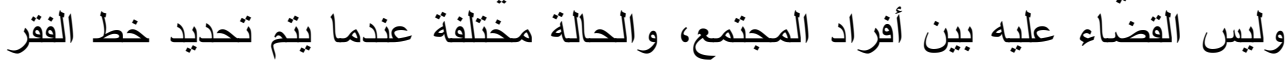

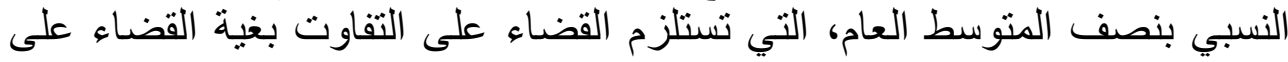

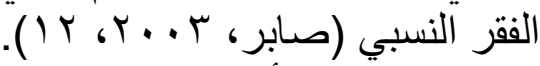

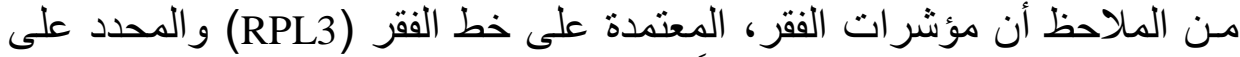

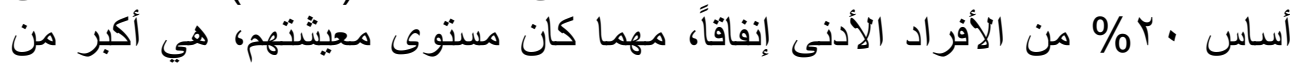

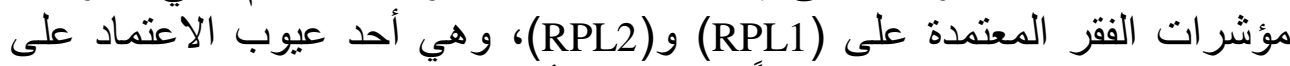

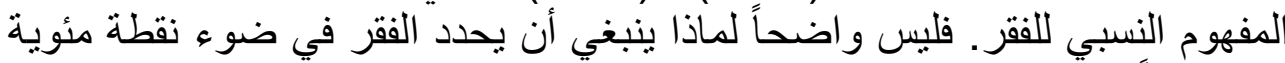

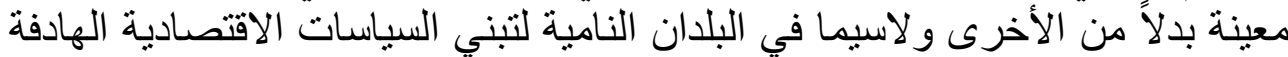

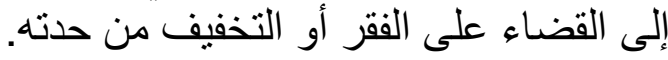
ع ـ الفقر الاجتهادي : كما ذكرنا في البند الخاص بصني الفياغة الإنموذج، لا بتم تحديد خط

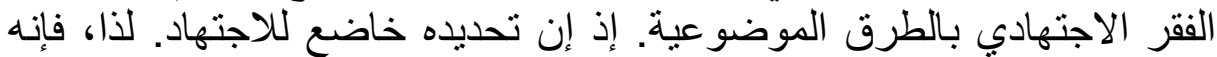

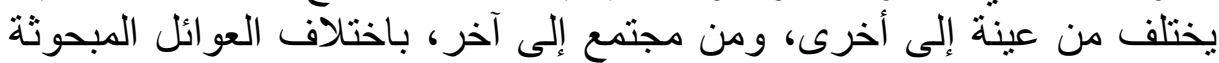
والتي تتأثز بجملة من العو امل والظروف المحيطة بها. ومع ذللك، تمّ تحديد هذا

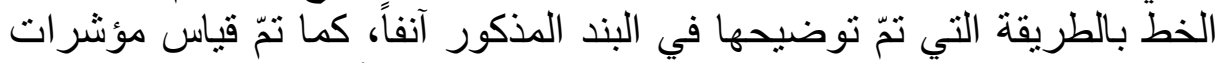
الفقر المناظرة لهذا الخط بالطرق المنهجية المماثلة لبقية أنواع الفقر.

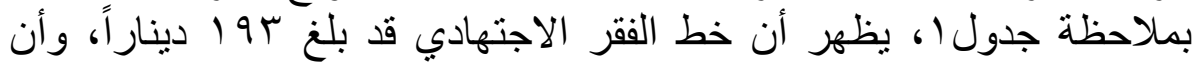

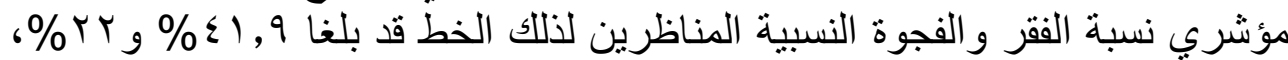

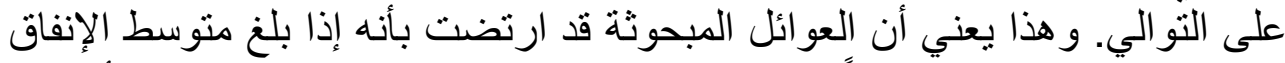

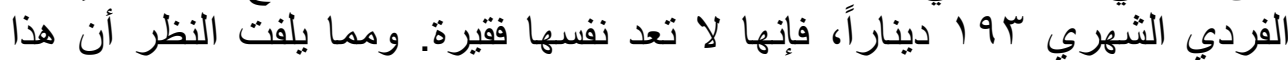

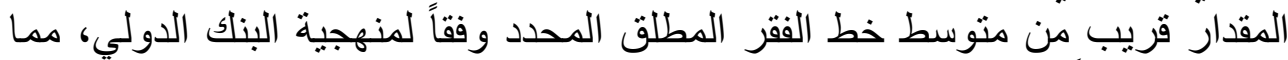

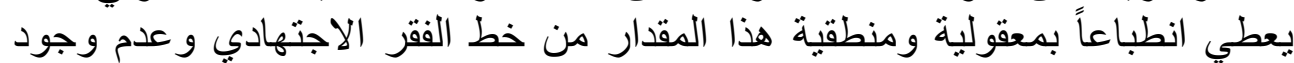

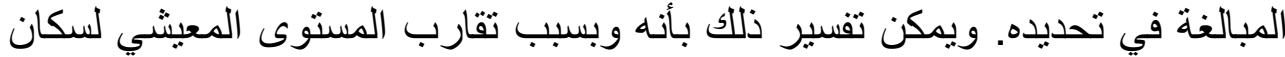

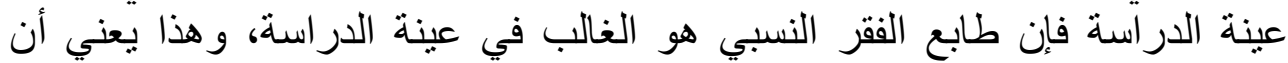

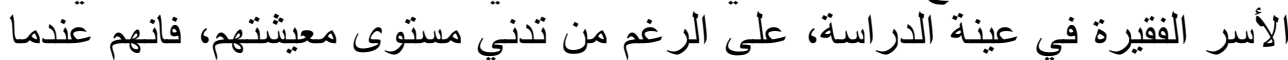

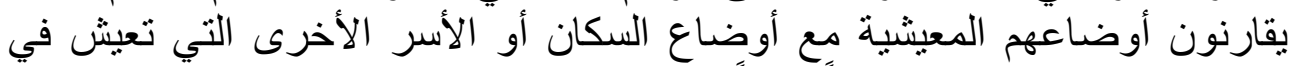

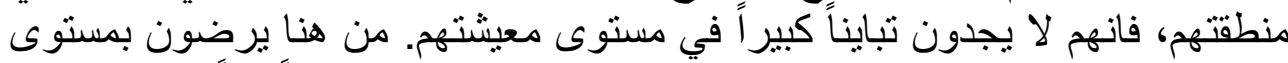

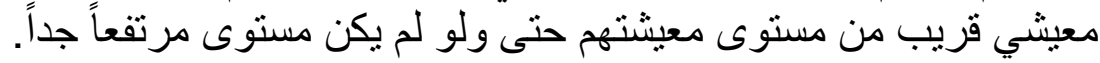

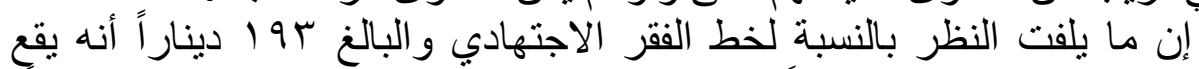

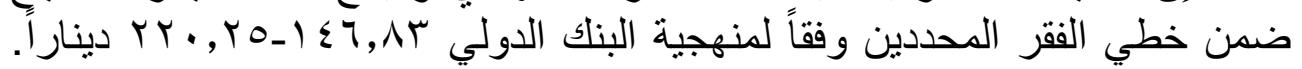




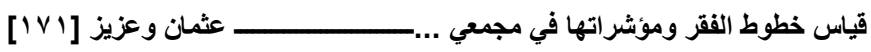

و هذه النتيجة تعزز تحفظاتنا السابقة بشأن انخفاض خطوط الفقر المطلق المحددة على التى

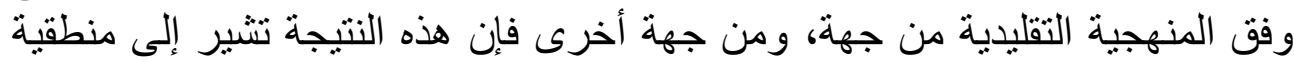
ومعقولية خط الفقر الاجتهادي المحدد لعينة الدراسة. ويمكن إعتماده على أساس كونه خطاً للفقر المطلق.

\section{الاستتتاجات والتوصيات

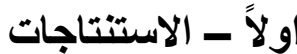

لقد توصلت الدراسة الحالية إلى جملة من الاستتناجات، أهمها:

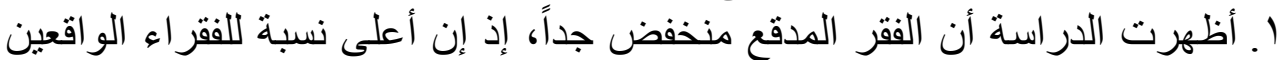

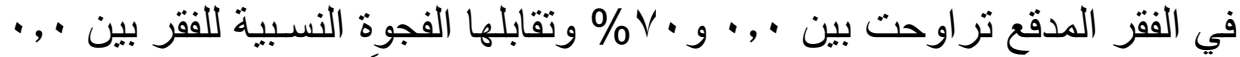

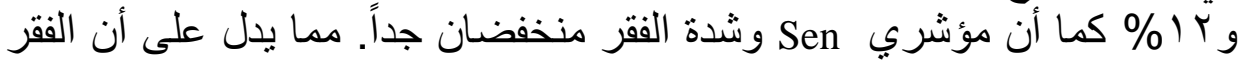

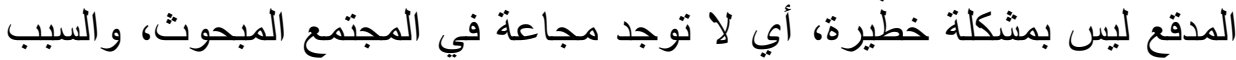

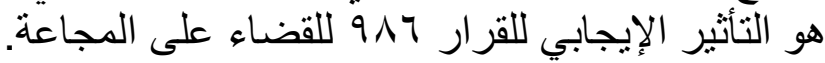

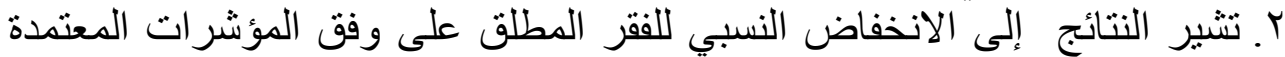

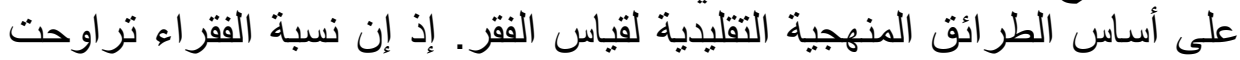

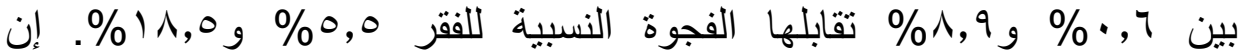

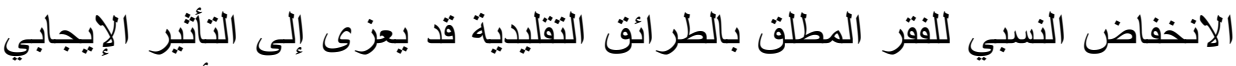

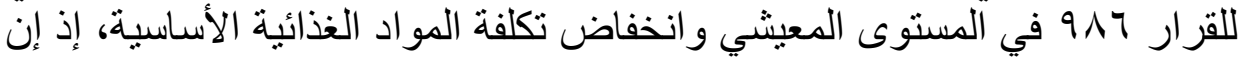
الإنفاق على البنود الغذائية المختلفة تشكل

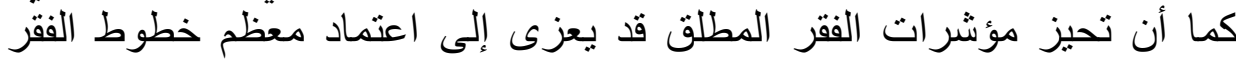

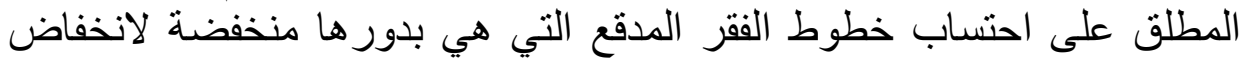

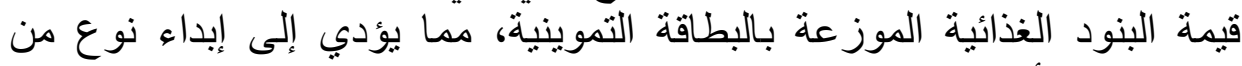

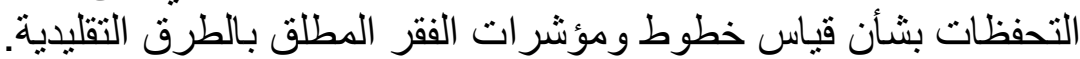

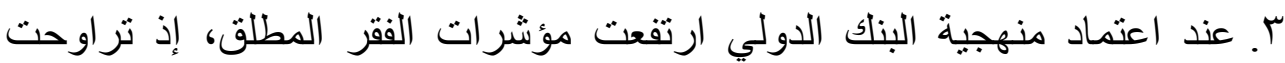

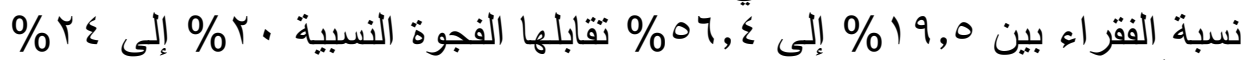

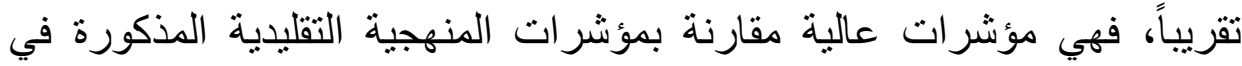

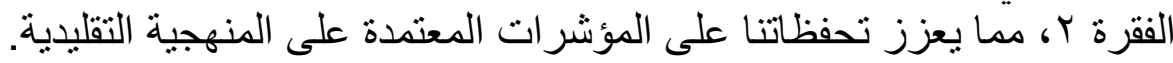

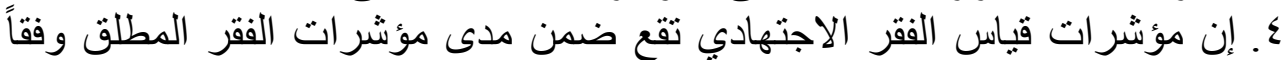

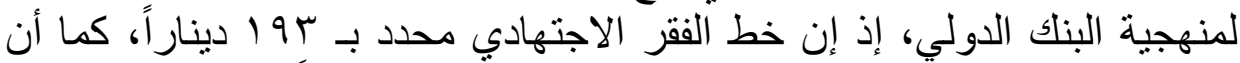

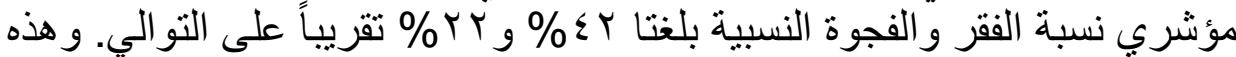

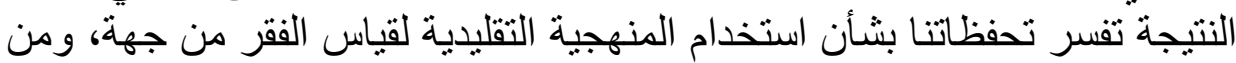

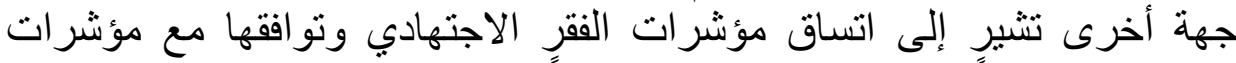

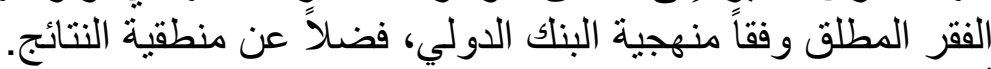

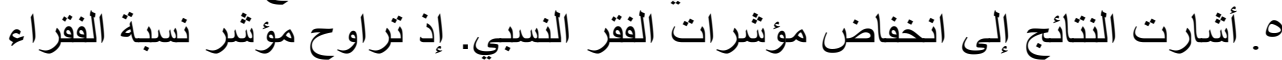

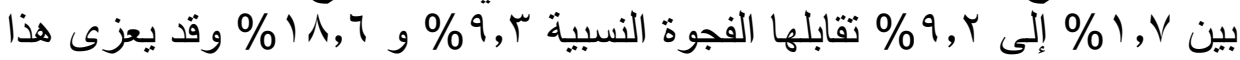
الانخفاض في مؤشرات الفر النسبي إلى الاعتدال النسبي في توزيع الإنفاق 
الفردي في عينة الدراسة. إذ إن قيمة معامل جيني، الذي يعد مقياساً شائعاً لقياس

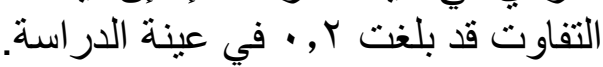
7 T. اتساق مؤشري Sen وشدة الفقر مع بقية المؤشرات، فعندما ترتفع قيم خط الفية الفقر

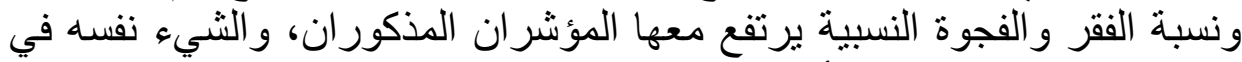

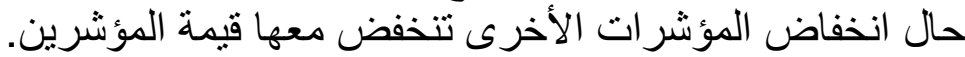

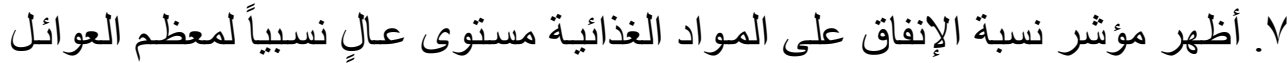

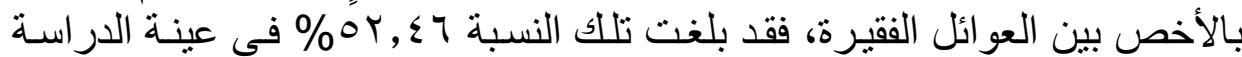

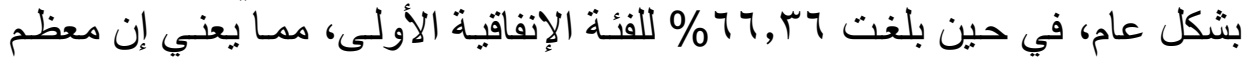
العو ائل لم تصل إلى مستوى الإشباع من المواد الغذائية.

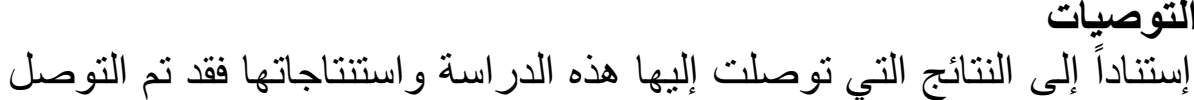

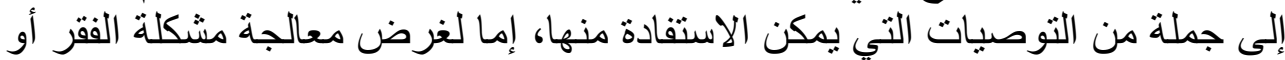

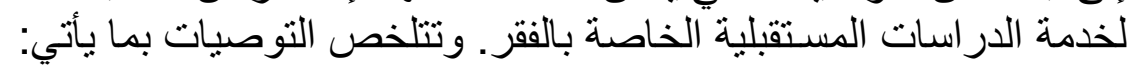

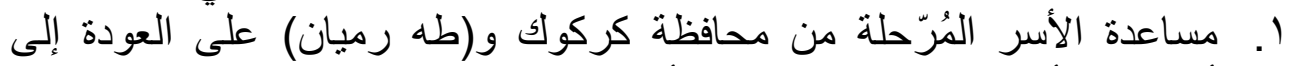

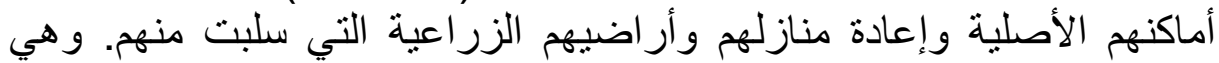

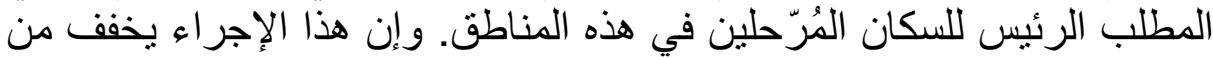

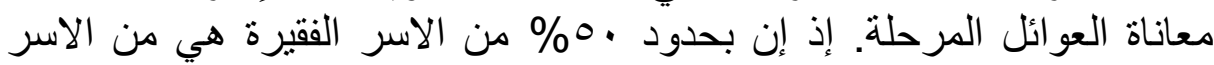

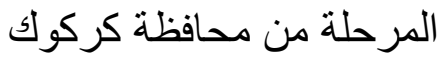

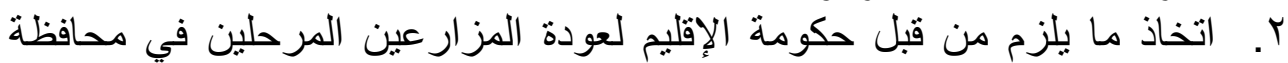

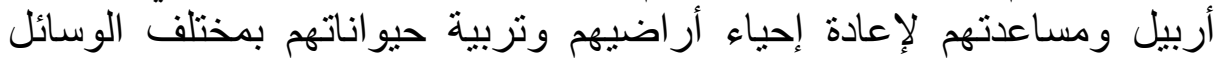

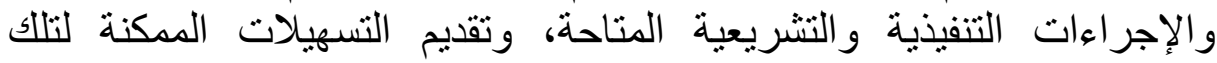

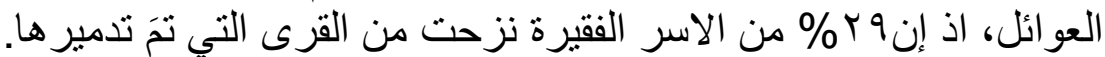

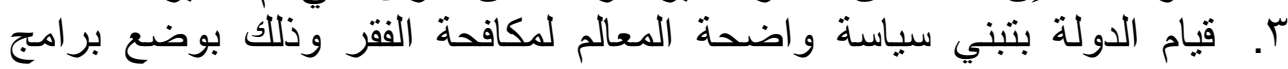

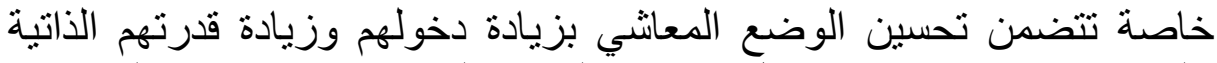

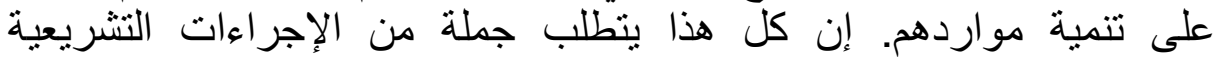

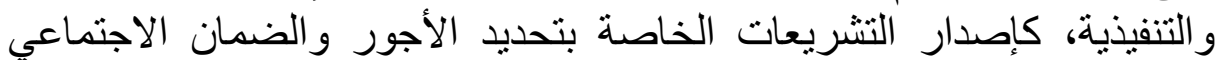

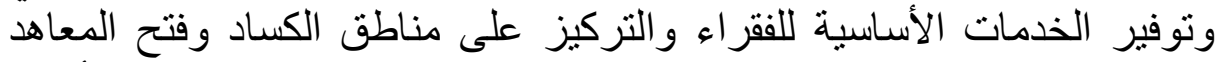
و المر اكز الخاصة بالتدريب لزيادة فرص العمال للحصول على التئ العمل بأجور أعلى ....... ألخ.

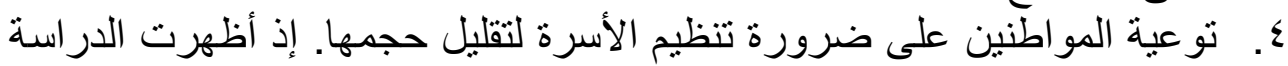

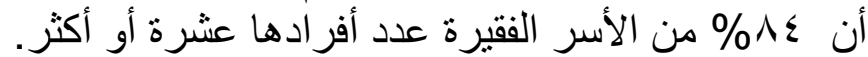

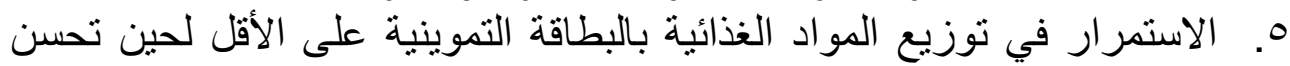

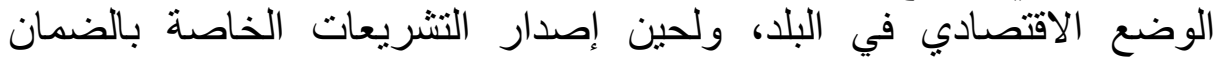

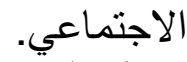
T. تفعيل الدوائر الإحصائية في الإقليم للقيام بجمع البيانات عن الدخول والإنفاق

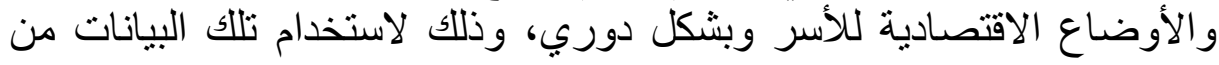




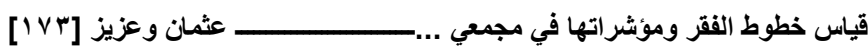

قبل الباحثين والجهات المعنية لإجراء دراسات عن الفقر بأبعاده كافة، كاتجاهه

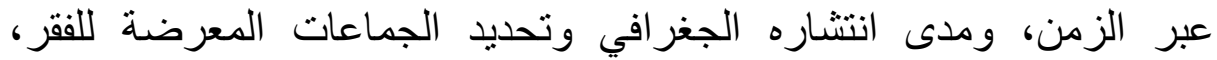
وغيرها من الأبعاد كتحديد العوامل المؤثرة في الفقر والسبل الكفيلة بالحد من

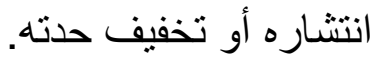

V. لقد أظهرت الدراسة اختلاف مؤشرات قياس الفقر تبعاً لاختلاف المفاهيم

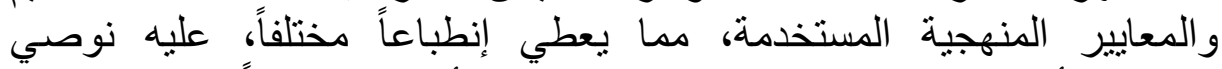

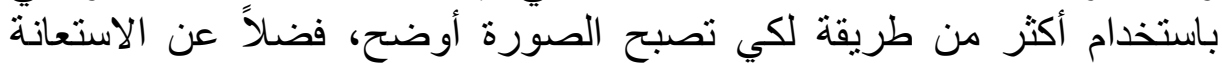

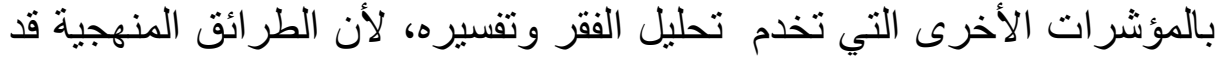

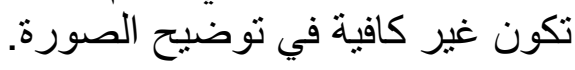

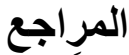 \\ أولاًا المراجع اجع باللغة العربية}

ا. باقر، محمد حسين، قياس الفقر في دول اللجنة الاقتصادية والاجتماعية لغربي آسيا، اللجنة اللإية

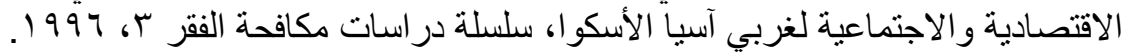

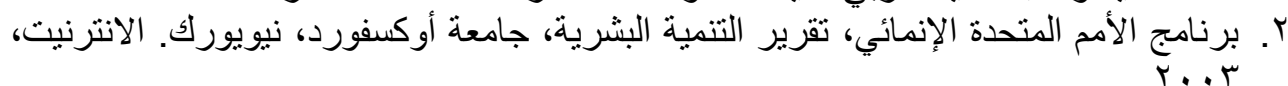

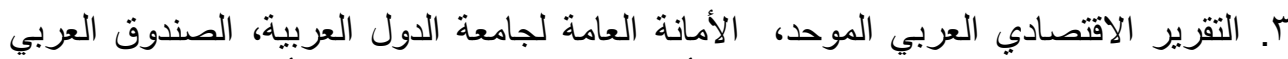

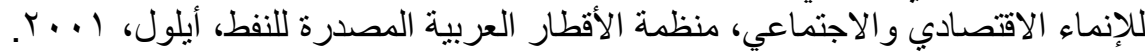

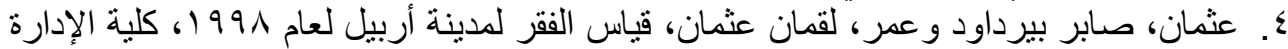

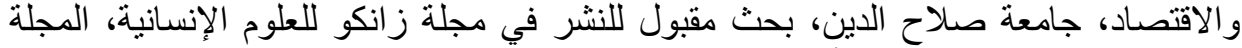

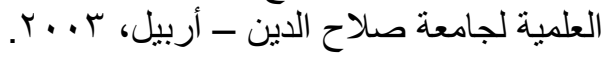

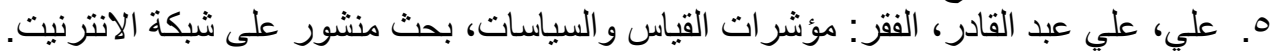

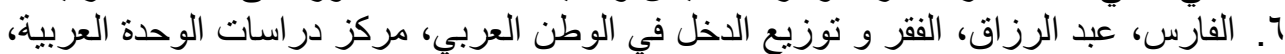

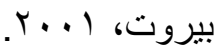

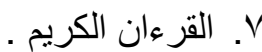

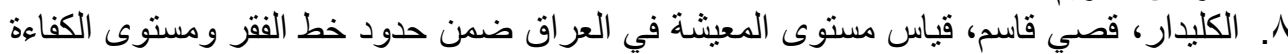

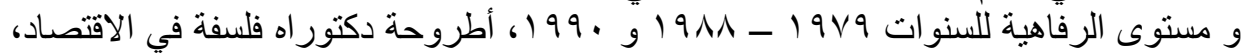

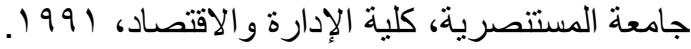

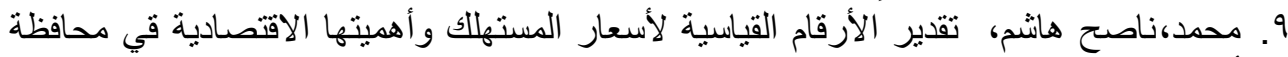

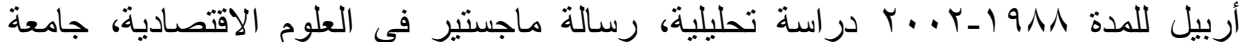

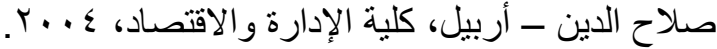

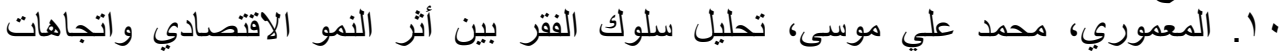

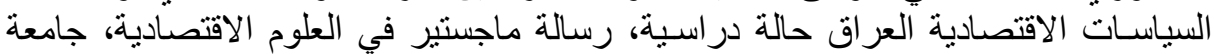

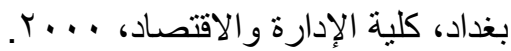

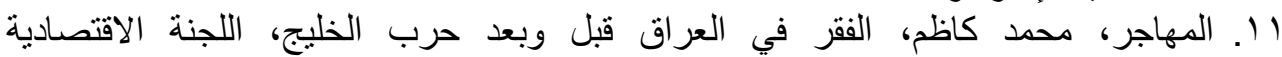

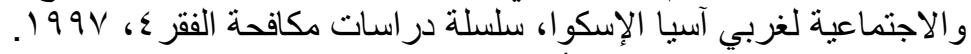

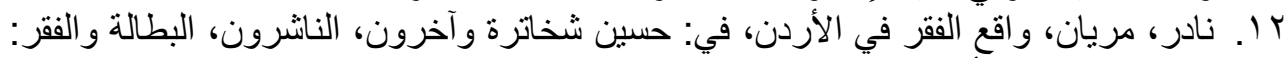

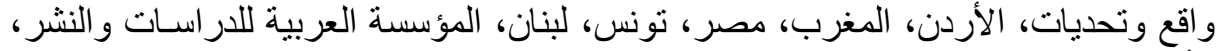

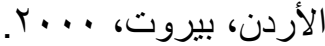


ז ا. النجفي، سالم توفيق، موروثات القرن العشرينمقاربات اقتصادية، بيت الحكمة، بغداد،

ـ ا. . ويبستر ، أندرو، مدخل لسوسيولوجية التنمية، ترجمة حمدي حميد يوسف، سلسلة المائة كتاب،

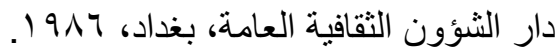

\section{ثانياً. المراجع باللغة الإنكليزية}

1. Atkinson, A. B., The Economics of Inequality، Oxford University, London, 1975.

2. Bernal, N.B., et.al., Measures of Poverty and Inequality: Philippine estimates and policy options, In slottje, Daniel, J., Dangum, Camelo and Lemmi, Achille (eds.), Income Distribution, Social welfare, Inequality, and poverty JAI, Press Inc., London, 1995.

3. George, V. and Lawson, R., Poverty and Inequality in Common Market Countries, Rout Ledge on Kegan Paul Ltd., London, 1980.

4. Pannuzi, N. and Quaranta, A. G., Measuring Poverty: Acase Study in An Italian Industrial City, In: Slottge, Daniel J. Dagum, Camilo and Lemmi , Achille (eds.), Income Distribution, Social Welfare, Inequality and Poverty JAI, Press Inc, London, 1995.

5. Sen, A., An Ordinal Approach to Measurement, Economitrica, Vol. 44, no. 2, 1976.

6. Townsend, Peter, The Measurement of Poverty, British, j. of Sociology, 1954.

7. www.imf.org, International Monitory Fund, Statically Appendix, Table 8, Summary of Inflation.

8. www.undp.org Lanjouw, J. O., Demystifying Poverty Line.

9. www.undp.org, United Nations Development Program (UNDP), Human Development Report (HDR) 1997, New York, Oxford University Press. 